\title{
Combined electromagnetic, geochemical and thermal surveys of Taal volcano (Philippines) during the period 2005-2006
}

\author{
J. Zlotnicki • Y. Sasai • J. P. Toutain • E. U. Villacorte • \\ A. Bernard • Julio P. Sabit • Juan M. Gordon Jr • \\ Ernesto G. Corpuz • M. Harada • J. T. Punongbayan • \\ H. Hase $\cdot$ T. Nagao
}

surveys were carried out to investigate self-potential, total magnetic field, ground temperature and carbon dioxide soil degassing, along with satellite thermal imaging of the Main Crater Lake. The elevated temperatures and high concentrations of carbon dioxide, as well as electromagnetic anomalies, indicate large-scale hydrothermal degassing. This process is enhanced along the tectonic features (e.g., crater rim and faults) of the volcano, while active fissures opened along the E-W northern flank during the 19921994 seismic activity. Heat and fluids from the hydrothermal system are essentially released in the northern part of the crater, which is bounded to the South by a suspected NW-SE fault along which seismicity seems to take place, and dikes are thought to be intruded. During the January

\section{A. Bernard}

Laboratoire de Géochimie et Minéralogie Appliquée,

Université Libre de Bruxelles,

CP160/02, avenue FD Roosevelt 50,

1050 Brussels, Belgium

M. Harada

Centre for Frontier Electronics and Photonics, Chiba University, 1-33 Yayoi-cho,

Inage-ku, Chiba 263-8522, Japan

H. Hase

Geological Survey of Japan, AIST, Tsukuba,

Tsukuba, Ibaraki 305-8567, Japan

T. Nagao

Earthquake Prediction Research Centre, Tokai University,

3-20-1, Orido,

Shimizu-ku, Shizuoka 424-8610, Japan 
2005 surveys, a new seismic crisis started, and the felt earthquakes prompted spontaneous evacuation of hundreds of inhabitants living on the volcano. Repeated surveys show changes of self-potential, total magnetic field, and ground temperature with time, without any noticeable spatial enlargement. These observations suggest that the northern flank located between the crater rim and the 19921994 fissures is connected with a deep thermal source in Main crater and is reactivated during seismic crises. This sector could be subjected to flank failure.

Keywords Self-potential $\cdot \mathrm{CO}_{2}$ soil degassing - Magnetic . Hydrothermal system · Volcanic hazard - Satellite monitoring $\cdot$ Taal volcano

\section{Introduction}

Eruptions from subduction-zone volcanoes are often preceded by phreatic events that result from either direct or indirect interactions between magma and well-developed hydrothermal systems. The occurrence of such events is related to a high degree of permeability and structural heterogeneities in the volcano. The study of volcanic systems and their thermal and hydrothermal disequilibrium is therefore a key step in the assessment of volcanic hazards.

The Taal volcanic complex in the Philippines is a $5-\mathrm{km}-$ diameter structure that has developed in the middle of a large (about $16 \times 27 \mathrm{~km}$ ) prehistoric caldera filled by Taal Lake ('TL', Fig. 1a and b). Taal volcano $\left(121^{\circ} \mathrm{E}, 14^{\circ} \mathrm{N}\right)$ is a 311-m-high stratovolcano with a lake (Main Crater Lake,
'MCL'; $75 \mathrm{~m}$ deep, $1.2 \mathrm{~km}$ in diameter) filling the central crater (called Main crater, 'MC'; i.e., Ramos 2001). This acid lake ( $\mathrm{pH} \sim 2-3$ ) is partially connected to Taal Lake ('TL') which surrounds the volcanic complex and which is itself rimmed by a larger prehistorical caldera. The volcano is located close $(60 \mathrm{~km})$ to Metro Manila on Luzon Island (Fig. 1a). Taal crater is similar in size to the Pinatubo 1991 crater (Ramos 2001). The volcano has been designated as one of the 15 "Decade Volcanoes" that represent especially high potential hazards to population centers. Since 1572, Taal has erupted at least 33 times killing more than 1,500 inhabitants. The destructive historical activity is mostly due to extensive contact between MCL, the near-surface water table, an active hydrothermal system, and the ascending magma. The volcano exhibits diverse activity such as gas eruptions, tsunamis, pyroclastic flows, ash surges, and mud outbursts. Electric (self-potential, 'SP'), magnetic (total magnetic field, 'TMF'), ground and water temperature ('GT' and 'WT') surveys, as well as geochemical (' $\mathrm{CO}_{2}$ ' soil degassing) mapping, are considered as the most effective methods for studying hydrothermal systems, due to their high sensitivity to fluid transfer in highly fractured media. In addition, such methods have already revealed transient signals related to volcanic unrest (Aubert and Baubron 1998; Hashimoto and Tanaka 1995; Johnston and Stacey 1969; Massenet and Pham 1985; Michel and Zlotnicki 1998; Sasai et al. 1990, 2002; Tanaka 1993; Yukutake et al. 1990; Zlotnicki and Le Mouël 1988; Zlotnicki et al. 2003).

This paper reports combined geophysical, geochemical, ground-based, and satellite observations on (1) the location of heat and fluid transfers, (2) interactions between these
Fig. 1 a Satellite view of Taal volcano within the lake Taal caldera. BUC is Buco magnetic reference station; b Topographic map of Taal volcano. Black points indicate the location of SP measurements. Yellow squares show the location on the 1992-1994 active fissures. Bottom left: Detail area of P4 and $\mathrm{P} 8$ surveys. Bottom right: Detail area of $\mathrm{P} 1$ and $\mathrm{P} 2$ surveys
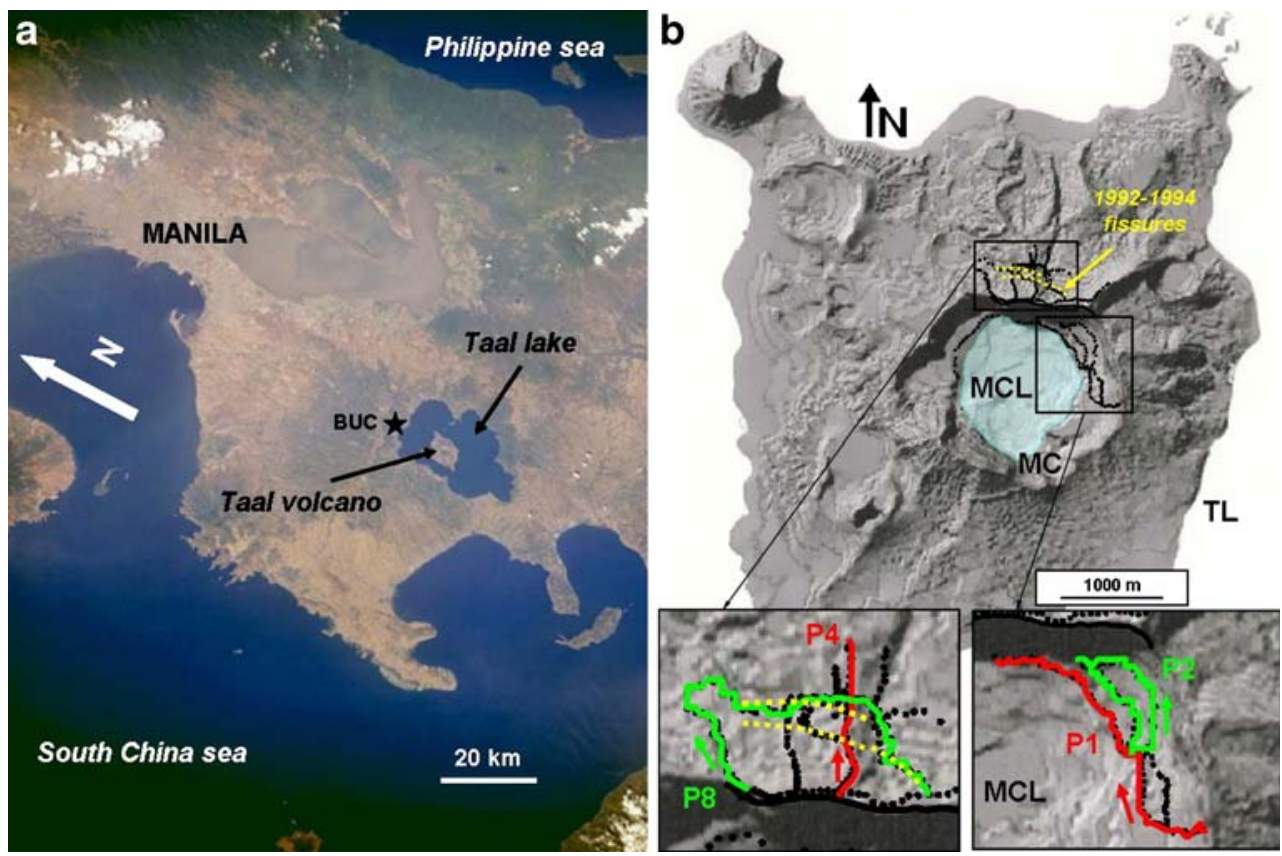
transfers and the main volcanic structures; and (3) temporal changes during the 2005-2006 period.

\section{Historical activity and current risk}

The most destructive historical eruptions are phreatomagmatic (1749 and 1965), plinian (1754), and phreatic (1911). Thick tephra deposits from the 1749 and 1754 eruptions have been recognized up to $16 \mathrm{~km}$ away from the volcano (Ramos 2001). The 1965 event was a high VEI (level 4 on an eight-level scale) eruption that affected an area of $60 \mathrm{~km}^{2}$ and killed about 200 people in spite of the evacuation of about 11,000 inhabitants. Pyroclastic surges characterized the last phreatomagmatic eruption in 1977, opening a new eruption center on the southwestern edge of MC. A large-scale eruption of Taal could trigger the evacuation of 100,000 people or more.

The time delay between two succeeding eruptions, as well as the type of activity, can provide valuable information on forthcoming activity (Fig. 2). Of historical eruptions, $88 \%$ have taken place after a repose period of less than 30 years. The last eruption occurred 30 years ago. Considering that the 1965 eruption was particularly destructive after 54 years of quiescence, this implies that the explosive activity might be high.

Taal volcano is attentively monitored by the Philippine Institute of Volcanology and Seismology (PHIVOLCS). Since 1994, it is considered to be in a possible state of unrest as seen from periodic seismic swarms, ground deformation, and changes in temperature and chemistry (http://www.phivolcs.dost.gov.ph). Alerts of level 1 on a five-level scale are regularly issued; one of these alert periods lasted from October 2004 to June 2005, and level 1 was again reached in December 2005.

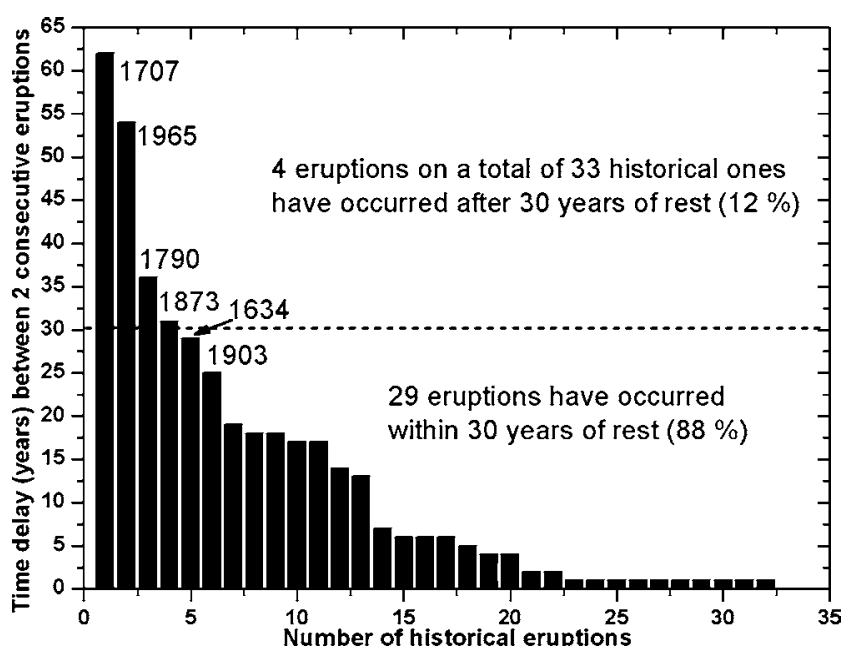

Fig. 2 Time delay between two consecutive eruptions as a function of the number of historical eruptions
The last strong surface activity started in 1992. During intense periods of seismic activity in 1992 and 1994, rapid ground deformation was observed, with an uplift of up to $21 \mathrm{~cm}$ in a day, while new fissures opened on the northern outer slope, and remarkable changes occurred in MCL water temperature and chemistry (Gabinette 1999). In particular, the strongest heating episode at MCL occurred in 1994-1995, when temperatures increased up to $39^{\circ} \mathrm{C}$ with a $\Delta T$ of $9-10^{\circ} \mathrm{C}$ (Poussielgue 1998). At that time, the thermal power dissipated by the lake surface peaked at $350 \mathrm{MW}$. This surface activity was interpreted as the result of dike intrusion in the volcano at a depth of less than $5 \mathrm{~km}$ (Bartel et al. 2003). A deflation was then observed in 1996 (Bartel 2002). Between 1998 and 2000, several new episodes of inflation and deflation were recorded by PHIVOLCS. A new inflation period occurred in 2000, with a 12-cm uplift of the volcano center corresponding to episodic intrusions of magma in a shallow reservoir (Bartel et al. 2003). On 23 September 2004, seismic activity increased, and a precise leveling survey in November indicated $5 \mathrm{~mm}$ of inflation on the SE volcano flank. Seismic swarms were recorded with a maximum of 20 daily events on 13 February 2005. During this period, the most significant earthquakes occurred on 9 January 2005, with an intensity of III. Hundreds of inhabitants spontaneously evacuated the Island for a few days under the supervision of PHIVOLCS. After February 2005, the number of earthquakes slowly decreased. Alert level 1 was issued in October 2004 and maintained until 30 June 2005. In December 2005, the level of alert was again raised to 1 when new seismic swarms were recorded.

\section{Interaction between the plumbing system and the aquifers}

Taal Lake was cut off from the South China Sea by the extensive deposits of the 1749 eruption. The water level is now $2 \mathrm{~m}$ higher than sea level, while the MCL is $2 \mathrm{~m}$ above TL level (Ramos 1986). Sulphur isotopes and halogen ratios in the lake water suggest that sea water infiltrates the volcano and the hydrothermal system (Fig. 3; Delmelle et al. 1998). The level of MCL can vary by up to $1 \mathrm{~m}$ depending on seasonal rainfall and volcanic activity (Poussielgue 1998). Therefore, the MCL volume (about $45 \times 10^{6} \mathrm{~m}^{3}$ ) can change by up to $2.6 \%$ within a few months. In turn, this can induce local stresses that probably affect groundwater flow and hydrothermal activity.

In volcanoes with crater lakes, where magmatic fluids are being injected and buffered by a large hydrothermal system, geothermal energy is essentially released through the main structures (faults, crater rims, cones, etc), porous and permeable media and crater lakes (Chiodini et al. 
Fig. 3 Simplified sketch showing possible fluid transfers through Taal volcanic system (after Delmelle et al. 1998)

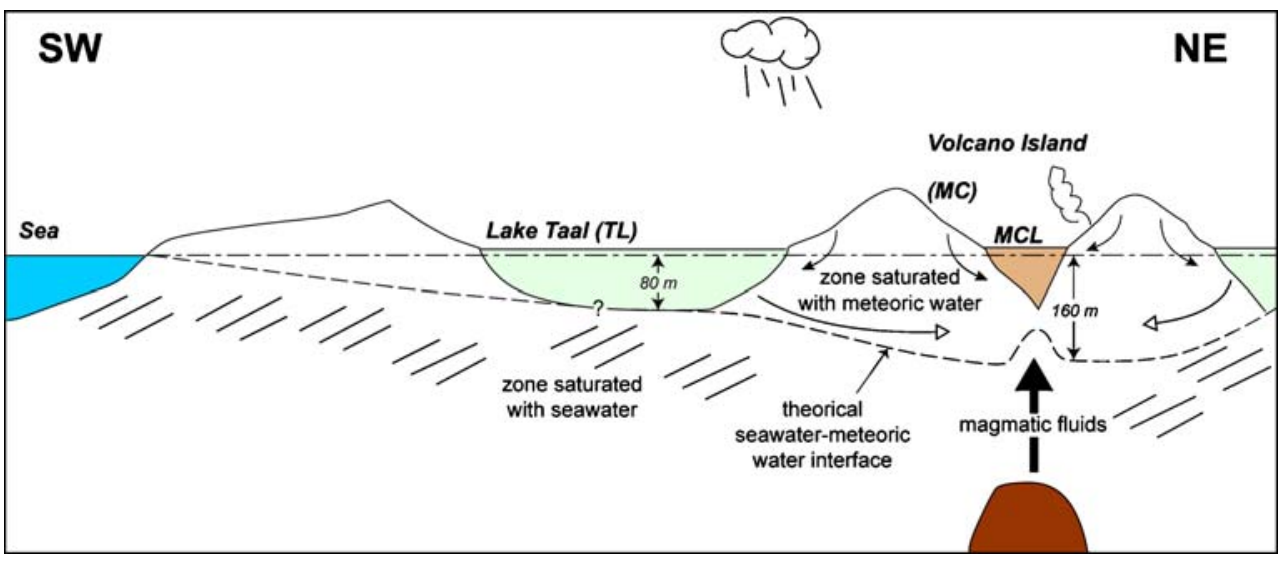

2005). In the case of Taal volcano, interactions between aquifer(s) below the MCL and rising magmatic fluids result in an active hydrothermal system expressed at the surface by acidic waters in the MCL ( $\mathrm{pH}$ of 2 to 3 ) and several areas undergoing evident extensive heat and gas transfer with temperatures reaching $100^{\circ} \mathrm{C}$.

The first key feature of Taal volcano is the importance of fluid-rock interactions. Most of the heat from the plumbing system is evacuated by the MCL and via open fracture zones. Because of this heat loss, the hydrothermal system slowly returns to a self-sealed system through fluid-rock interactions that lead to alteration and mineralization of the rocks, in a similar way to Soufrière volcano on Guadeloupe (Zlotnicki et al. 1992). Typically, this may induce a simple scenario whereby an increase in the thermal stress field up to a local threshold can potentially trigger a moderate eruption. Another scenario involves fast injection of dikes in the hydrothermal system, which can rapidly produce a vigorous phreatic to phreatomagmatic eruption. The dynamics of this eruption may be controlled by the thermal budget and by argillization of the hydrothermal system and overlying pile.

The second key feature of the volcano is the high permeability and porosity of the rocks. This produces considerable ground deformation associated with seismic swarms, leading to a pattern that is often considered as possible precursor sign of eruptive activity (Bartel et al. 2003). However, the 1982-1984 bradyseismic crisis of Campi Flegrei in Italy, which is also associated with a large hydrothermal field, gave rise to a huge deformation that was not followed by any eruption (Di Vito et al. 1999; Gaeta et al. 1998). This feature is highly characteristic of quiescent volcanoes exhibiting large-scale hydrothermal systems, which makes it difficult to forecast an eruption using seismic and deformation patterns alone (Chiodini et al. 2001).

The above discussion stresses the need to establish a detailed delineation of the hydrothermal system and the connections between the refilling water and the plumbing system. For this purpose, we performed $\mathrm{SP}, \mathrm{TMF}, \mathrm{CO}_{2}$, and GT surveys combined with satellite thermal imaging of the MCL.

\section{Methodology}

In 2004, PHIVOLCS signed an agreement with the working group on ElectroMagnetic Study of Earthquakes and Volcanoes (EMSEV) on behalf of the International Union for Geophysics and Geodesy (IUGG), for developing electromagnetic studies on Taal. The aim of this project is to obtain a better understanding of the volcanic structure and the hydrothermal system, and contribute to the monitoring of the ongoing activity.

Self-potential and ground temperature profiling The selfpotential method consists of measuring the static electric potential difference between a reference point located outside the hydrothermal system, considered as a relative zero potential, and a running point along a progressively unrolled cable (i.e., Sato and Mooney 1960; Zohdy et al. 1973). The measurements are carried out using nonpolarizing electrodes (see Perrier et al. 1997). Although several phenomena contribute to creating SP anomalies, the two main mechanisms encountered on volcanoes are due to electrokinetic and thermoelectric effects (Corwin and Hoover 1979; Ishido and Mizutani 1981; Nourbehecht 1963; Overbeek 1952). It is commonly assumed that upward migrating fluids generate positive anomalies, whereas infiltrating fluids produce negative anomalies. This phenomenon is most often characterised by the so-called topographic effect, which corresponds to a negative linear trend between the elevation of measurement points and the SP values (see review by Zlotnicki and Nishida 2003). However, we should also consider other mechanisms for transient effects related to fluid disruption or seismicity (Byrdina et al. 2003; Johnston et al. 2001). The amplitude of SP anomalies can be up to several hundreds of millivolts 
over distances of $1 \mathrm{~km}$ (Ballestracci and Nishida 1987; Di Maio et al. 1996; Finizola et al. 2004; Friedel et al. 2004; Hashimoto and Tanaka, 1995; Lewicki et al. 2003a; Sasai et al. 1997; Zlotnicki et al. 1998).

On Taal volcano, SP surveys were performed with insulated 2-km-long copper reels, a high impedance meter $\left(10^{7} \Omega \mathrm{m}\right)$ and $\mathrm{Pb}-\mathrm{PbCl}_{2}$ nonpolarizing electrodes (Petiau 2000). Profiles were measured with a mean interval of $25 \mathrm{~m}$, using local zero potential references (Fig. 1b). Several measurements were made at survey points and then averaged $(|\max -\min |<5 \mathrm{mV})$. All surveys were normalized to a unique reference potential, which is taken as zero along the TL shoreline. The error is less than $25 \mathrm{mV}$ along closed loops of several kilometers length.

Ground temperature was simultaneously measured at the same SP locations at about $15 \mathrm{~cm}$ depth with a digital thermometer. The uncertainty on the temperature measurement is estimated at $0.5^{\circ} \mathrm{C}$.

Magnetic survey Changes in stress field (piezomagnetic effect), ground temperature (thermal magnetic effect), and ground fluid circulation (electrokinetic effect) are the most effective mechanisms generating magnetic fields associated with volcanic activity. In particular, a change in ground temperature is the most common cause of volcano-magnetic phenomena of shallow origin. The presence of shallow hydrothermal and groundwater systems, and the ascent of hot magma (i.e. Sasai et al. 1990), can produce changes of a few tens of nanoTesla in the geomagnetic field, with the result that TMF surveys provide a good indicator of forthcoming surface activity (Tanaka 1993; Hurst et al. 2004). Magnetic measurements were performed using three proton precession magnetometers. An Overhauser-type magnetometer (0.01 nT accuracy, $5 \mathrm{~s}$ sampling step) was used for continuous observations at the BUC reference station located near Buco volcano observatory (PHIVOLCS) on the northern shore of TL (Fig. 1a). During the first survey (Jan. 2005), the total magnetic field (TMF) was measured at intervals of $25 \mathrm{~m}$ along the same profile as $\mathrm{SP}, \mathrm{CO}_{2}$, and GT. Another Overhauser-type magnetometer was used for the magnetic survey, in which TMF values at each site were averaged over three points located within $20 \mathrm{~cm}$; the diurnal geomagnetic variation was removed by simply subtracting the differences between each site and the Buco reference station (Harada et al. 2005).

An ordinary proton precession magnetometer $(0.1 \mathrm{nT}$ accuracy) was used mainly at 21 repeat survey points, which cover three geothermal areas (the eastern shore of MCL, the northern slope of the volcano, called Daang Kastila, and the western shore of the MCL (Fig. 4). A benchmark was chosen when the horizontal gradient of TMF was less than $5 \mathrm{nT} / \mathrm{m}$. In this study, we used the same magnetometers at BUC reference station as in the repeat

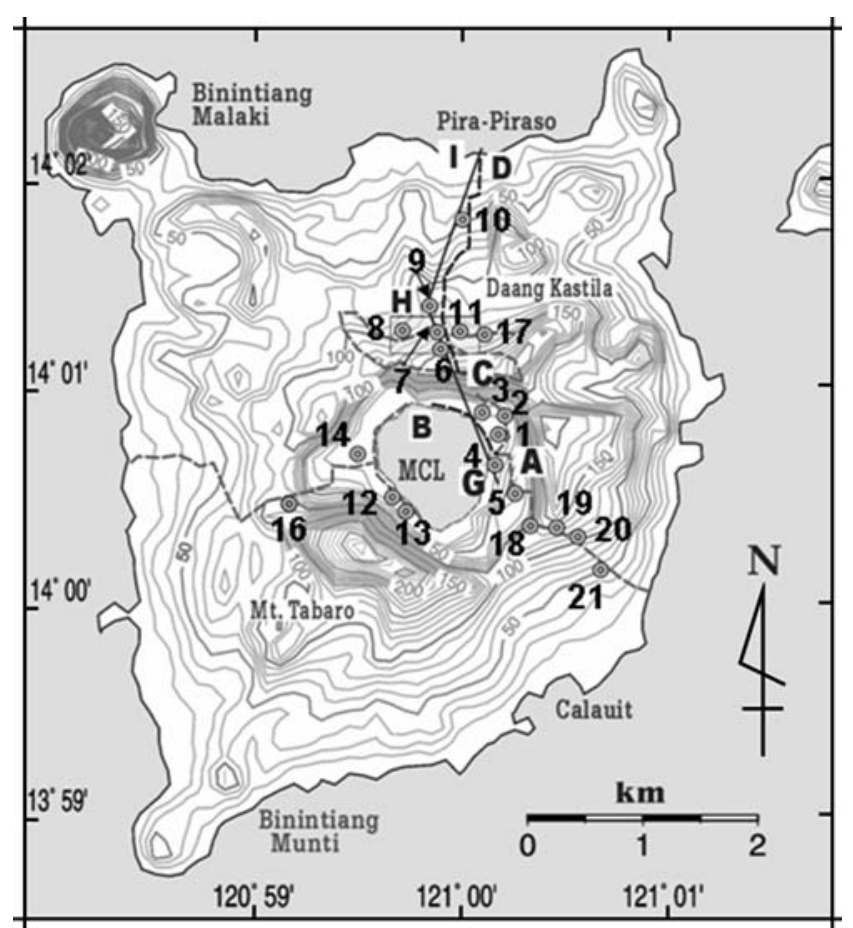

Fig. 4 Distribution of repeat magnetic survey points (circles)

surveys. TMF data from the Muntinlupa magnetic observatory located south of Manila were supplied by National Map and Resources Information Authority (NaMRIA) as reference data for repeat surveys, although they were not available during the first survey in January 2005.

Figure 4 shows the distribution of repeat magnetic survey points. It also includes a portion of the profiles derived from joint TMF and SP measurements. The line $A-B$ is located along the eastern shore of MCL ( $\mathrm{P} 1$ in Fig. $1 \mathrm{~b}$ ), while $C-D$ follows the horse trail on the northern flank of the volcano (P4 in Fig. 1b). Both lines cross prominent geothermal areas. Note that the two lines are separated by steep cliffs on the northern wall of MC.

$\mathrm{CO}_{2}$ soil degassing Degassing of magmatic/hydrothermal species through distal areas is known to occur on dormant to active volcanoes. Although this degassing may be visible (fumaroles, mofettes, and hot springs) it can also be absent (Allard et al. 1991; Baubron et al. 1991). Because of groundwater boiling and/or dissolution of volcanic gases in superficial aquifers, the soil gas phase is composed mainly of poorly soluble species, typically $\mathrm{CO}_{2}$ enriched in $\mathrm{He}$ and $\mathrm{Rn}$ and rarely in $\mathrm{CH}_{4}$. This phase is depleted in the more soluble species $\left(\mathrm{HCl}\right.$ and $\mathrm{SO}_{2}$ ). Because of convective/ advective transport, high $\mathrm{CO}_{2}$ fluxes can be released and may contribute to $20-50 \%$ of the total flux for a given volcano (Baubron et al. 1990; Cardellini et al. 2003; Farrar et al. 1995). Distal leaking is spatially heterogeneous because faults, fractures, and discontinuities act as conduits and/or barriers with respect to the gas phase according to 
their lithological, mineralogical, and mechanical properties. Therefore, mapping soil gas heterogeneities (through flux or concentration measurements) on a volcano is a powerful method for visualizing the distribution of discontinuities and the extent of fluid transfer, as well as the interactions between fluids and the main structural features (faults, fractures, rims, and craters).

Three main sources of carbon can contribute to the soil $\mathrm{CO}_{2}$ flux (magmatic, sedimentary, and biogenic carbon), and this can lead to a spatial heterogeneity in their relative concentrations in the soil gas (Fig. 5). Sharp carbon dioxide anomalies, sometimes with very high concentrations (up to $100 \%$ of total gases), are known to mark out fractures closely related to hydrothermal and/or volcanic sources (Baubron et al. 1990, 1991; Todesco et al. 2003). However, low-level anomalies (a few \%) due to enhanced biogenic activity in volcanic or faulted areas can also mark nonactive superficial fractures (Lewicki et al. 2003b; Toutain et al. 2002). Evidence has been reported of $\mathrm{CO}_{2}$ increase before eruptions or dike emplacement (Hernandez et al. 2001; McGee et al. 2000), making soil $\mathrm{CO}_{2}$ monitoring a powerful tool for detecting pre-eruptive processes. Moreover, the measurement of soil $\mathrm{CO}_{2}$ fluxes at Campi Phelegrei (Chiodini et al. 2001) has revealed the triggering of bradyseismic events due to the role of $\mathrm{CO}_{2}$-rich fluid injection at the base of a shallow hydrothermal system (Chiodini et al. 2003).

During field work on Taal, we only considered $\mathrm{CO}_{2}$ concentrations. We used metallic probes buried in the ground at a depth of about $70 \mathrm{~cm}$. Soil degassing concentrations were simultaneously measured during SP surveys, with a mean interval of $25 \mathrm{~m}$. The soil atmosphere was sampled with an electric suction pump at a rate of 1 1/min and injected into a LFG20 (Geogas, UK) Infra-Red analyzer for simultaneous and online measurement of $\mathrm{CO}_{2}$, $\mathrm{CH}_{4}$, and $\mathrm{O}_{2}$. The precisions of $\mathrm{CH}_{4}$ and $\mathrm{CO}_{2}$ measurements are $\pm 0.5,3$, and $5 \%$ for concentration ranges of $0-10$,

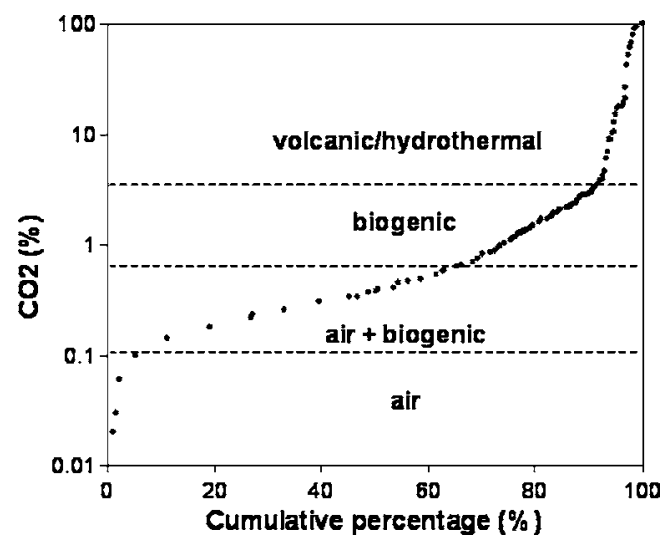

Fig. 5 Cumulative frequency distribution of $\mathrm{CO}_{2}$ measured in Taal soils. Populations are suggested by inflexion points
$10-50$, and $50-100 \%$, respectively. The precision of $\mathrm{O}_{2}$ measurement is $\pm 0.4 \%$.

In this study, $\mathrm{CO}_{2}$ measurements cover a wide range of concentrations, from 0.02 to $100 \%$. Isotopic analyses are currently used to distinguish the origin of the carbon, as ${ }^{13} \mathrm{C} /{ }^{12} \mathrm{C}$ ratios show strong differences between magmatic fluids, sedimentary carbonate, and organic matter $(-6 \pm 2$, $0 \pm 1,-25 \pm 5 \%$, respectively). However, recent results suggest that significant isotopic fractionation may occur in soils due to diffusive vs. advective contributions, thus casting some doubt on the $\delta^{13} \mathrm{C}$ parameter (Camarda et al. 2007). No isotopic analyses are available in the present study, so we use a graphical analysis to analyze the source of $\mathrm{CO}_{2}$ (cumulative frequency diagrams which identify populations as straight lines). This method is frequently used to display the asymmetric shape of skewed population distributions (Klusman 1993).

Satellite thermography Volcanic lakes act as calorimeters trapping most of the heat released by the magmatichydrothermal system. Lake temperatures reflect the balance between heat input from hydrothermal fluids and heat output by radiation and evaporation from the lake surface to the atmosphere. In this way, lake-surface temperature represents a key parameter for detecting changes occurring in the activity of a volcano. Surface temperatures of MCL were determined using data supplied by advanced spaceborne thermal emission and reflection Radiometer (ASTER). ASTER is an advanced multispectral sensor covering a wide spectral region from visible to thermal infrared. ASTER has 14 different spectral bands: three in the visible (VNIR: $0.52-0.86 \mu \mathrm{m}$ ), six in the near-infrared (SWIR: 1.60 $2.43 \mu \mathrm{m}$ ), and five in the thermal infrared (TIR: 8.12 $11.65 \mu \mathrm{m})$. The TIR bands with a spatial resolution of $90 \mathrm{~m}$ allow us to detect small thermal anomalies (a few degrees Celsius) and perform thermal mapping and monitor temporal variations in the lake surface temperatures. The surface of MCL (about $1.2 \mathrm{~km}^{2}$ ) is well adapted to using ASTER with a little more than 150 individual pixels available for temperature sampling.

Determination of the MCL surface temperatures using ASTER data was performed following the procedure developed by Bernard (2008). This technique is based on the classical split-window method, which has been successfully used with other satellites to obtain accurate sea surface temperatures (SST). The split-window method is based on establishing an empirical relationship between water temperatures measured at the surface and brightness temperatures measured in at least two TIR channels. The effects of atmospheric vapor and other absorbing components are removed by using a differential absorption measurement based on two TIR channels. The principal advantage of this approach is that it corrects the atmo- 
spheric effects on a pixel by pixel basis, i.e., for the local atmosphere and at the exact time the satellite is collecting TIR data. With ASTER data, we calculated the difference in brightness temperatures between bands 13 and 14 to remove the atmospheric effects.

\section{Observations}

Ground SP, GT, and $\mathrm{CO}_{2}$ surveys Combined SP, GT, and $\mathrm{CO}_{2}$ and TMF measurements were generally implemented along the same profiles. In several cases, TMF measurements were also performed on the same lines. In the following, we present four profiles (Fig. 6 a, b, c and d); the locations are given in Fig. 1b. P1 and P2 traverse the geothermal area in the northern part of MC, while P4 and P8 extend across the geothermal area on the northern volcano slope (Daang Kastila area).

Profile P1 The profile starts on the SE inner border of MC, at $150 \mathrm{~m}$ a.s.l., passes inside the crater, and then follows the northern MCL shoreline northwestwards towards the cliff across a hydrothermalized area exhibiting solfatara, fumaroles, hot springs, and gas bubbling in the MCL (Figs. $1 \mathrm{~b}$ and 6a). To the southeast, we find a geothermal area delimited by a negative SP anomaly $(150 \mathrm{mV}, 300 \mathrm{~m}$ wide). This is followed by a $700-\mathrm{m}$-wide GT anomaly along the MCL shore, which is composed of three subset peaks (up to $100^{\circ} \mathrm{C}, 200 \mathrm{~m}$ wide). A 600 -m-wide $\mathrm{CO}_{2}$ anomaly is superimposed onto the GT anomaly (some missing $\mathrm{CO}_{2}$ data are due to the sealing of probes). The main $\mathrm{CO}_{2}$ anomaly is composed of at least two sub-anomalies, with concentrations accounting for up to $100 \%$ of the soil gas, which are well correlated with the GT anomalies. Across the geothermal area, SP values decrease smoothly with short-wavelength anomalies (50 to $100 \mathrm{~m}$ in width) along the shore line.

Profile P2 P2 is a closed loop situated to the east of the MCL shore line. It follows the northern rim and returns to the starting point $50 \mathrm{~m}$ east of the shoreline (Figs. $1 \mathrm{~b}$ and $6 \mathrm{~b}$ ). A main GT anomaly ( $300 \mathrm{~m}$ wide, up to $75^{\circ} \mathrm{C}$ ) is located along the inner northern rim of MC. A weaker GT anomaly is observed at the end of the loop, in agreement with the margin of the GT anomaly described in P1. Corresponding low-level (a few \%) $\mathrm{CO}_{2}$ anomalies are recorded. Along the first $300 \mathrm{~m}$ of profile, the negative relationship between the SP values and elevation $(-1.5 \mathrm{mV} / \mathrm{m})$ corresponds to a local topographic effect. This linear trend is abruptly disrupted by a sharp negative SP anomaly of $60 \mathrm{mV}$ amplitude correlated with the largest GT and $\mathrm{CO}_{2}$ anomalies. At the end of the profile, the 100-m-wavelength SP anomaly of $50 \mathrm{mV}$ corresponds to the weaker $\mathrm{GT}$ and $\mathrm{CO}_{2}$ anomalies.
Profile P4 The P4 line carried out on 9 January 2005 runs nearly straight $\mathrm{N}-\mathrm{S}$ from $\mathrm{MC}$ rim toward $\mathrm{TL}$, intersecting the E-W-trending 1992-1994 fissures (Figs. $1 \mathrm{~b}$ and 6c). Two well-identified anomalies (GT up to 59 and $70^{\circ} \mathrm{C} ; \mathrm{CO}_{2}$ up to 4 and 100\%) are detected above the 1992-1994 fissures, the highest amplitudes of GT and $\mathrm{CO}_{2}$ corresponding to the northernmost active fissure. Only weak $\mathrm{CO}_{2}$ anomalies appear north of the most active fissures. The SP traverse is typical of active volcanic hydrothermal systems (e.g. Zlotnicki and Nishida 2003). High SP values are observed with a peak directly above the most active fissures. Then, values drop drastically by $205 \mathrm{mV}$ in amplitude over a distance of $50 \mathrm{~m}$ before slowly increasing along two offset segments leading up to TL. This slow recovery of zero potential corresponds to a $-1.2 \mathrm{mV} / \mathrm{m}$ topographic effect.

Profile $P 8$ The traverse starts from the external MC rim $400 \mathrm{~m}$ to the west of reference point P4 (Fig. 1b). The line descends to the northwest, then passes eastward through the geothermal area along the active fissures, and reaches the MC rim in the east (Fig. 6d). Prominent anomalies in GT, $\mathrm{CO}_{2}$, and $\mathrm{SP}$ occur in the same area and allow us to delimit the extent of the geothermal field. The SP anomalous area is expressed by scattered values on which are superimposed 250 -m-wide anomalies. No clear topographic effect is observed along the traverse.

Satellite thermal imaging of MCL Figure 7 is a processed ASTER image (TIR band) obtained during the night of 24 January 2003. The most noticeable thermal anomaly, about $650 \mathrm{~m}$ in width, lies along the northern shoreline of the MCL where we observe strong gas bubbling and solfatara. Two hot spots are clearly observed along this thermal anomaly. Their WTs are $35.7^{\circ} \mathrm{C}$ and $34.2^{\circ} \mathrm{C}$, respectively, while the average MCL temperature is $29.5^{\circ} \mathrm{C}$. The temperature difference between MCL and TL is $3.1^{\circ} \mathrm{C}$.

As both lakes have almost the same elevation, TL can be used as a reference to remove the influence of atmospheric temperature. During non-eruptive activity, the temperature of MCL is always a few degrees above that of TL. The thermal anomaly $(\Delta T)$, calculated as the temperature differences between the two lakes, remained almost constant during 2000-2006 $\left(2.5 \pm 0.7^{\circ} \mathrm{C}\right)$. At present, the thermal power dissipated by the lake surface is less than $50 \mathrm{MW}$.

Ground magnetic survey The geomagnetic inclination around Taal volcano is about $14^{\circ}$, i.e., almost horizontal. In such a setting, the intensity of the magnetic field or TMF decreases above a strongly magnetized body, while it increases above a weakly magnetized body. One possible origin for this could be high ground temperature. In a 3-D complex topography, the magnetic material in a lateral 

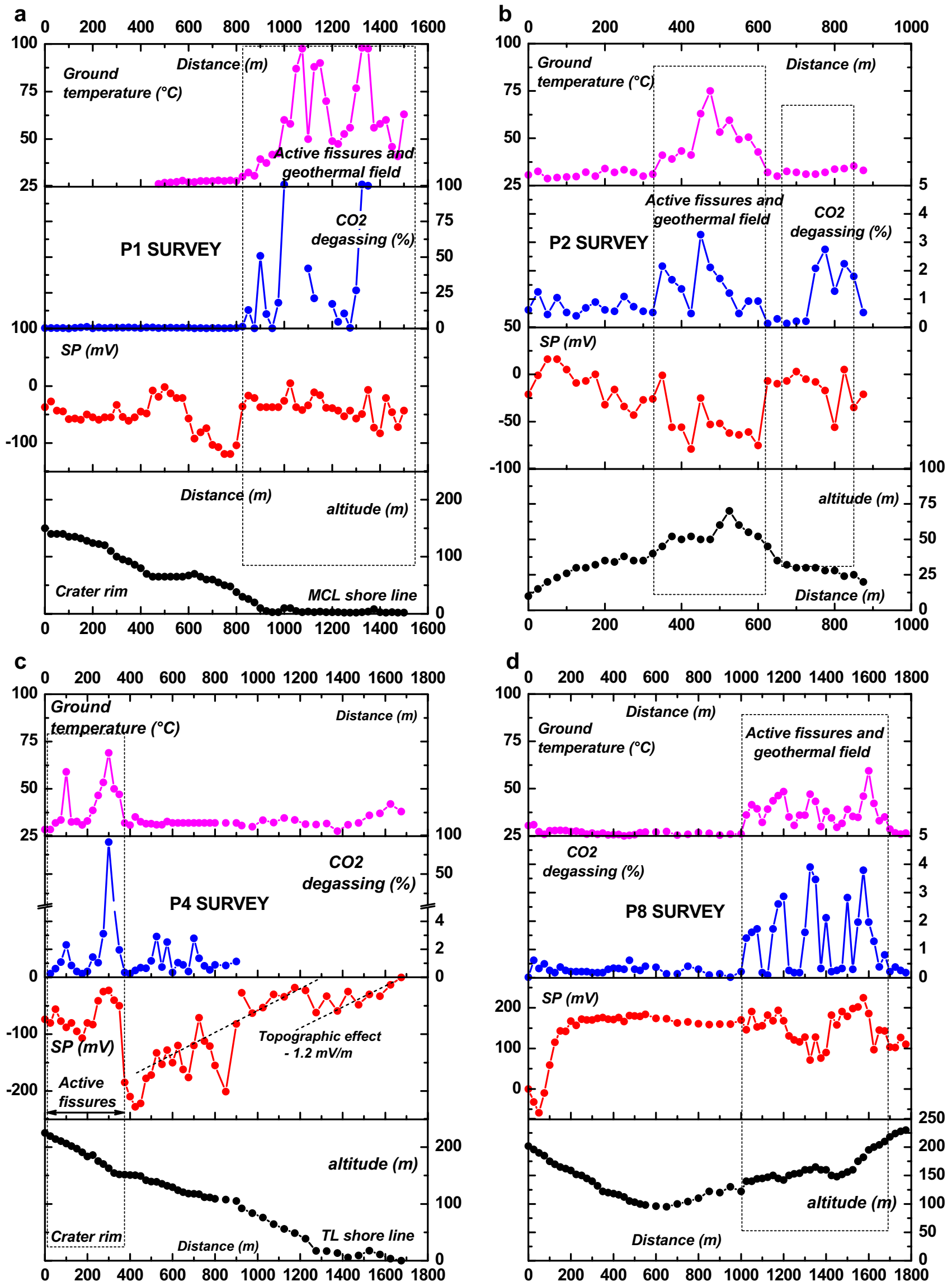
1Fig. 6 Comparison between topography, $\mathrm{SP}, \mathrm{CO}_{2}$, and ground temperature data, along four profiles. Rectangles indicate the location of anomalies. a Profile P1; b Profile P2; c Profile P4; d Profile P8. See Fig. $1 \mathrm{~b}$ for location of the profiles

position contributes significantly to the TMF. Hence, the local magnetic field does not always reflect the magnetization just beneath the observation site. This is contrary to the SP, GT, and $\mathrm{CO}_{2}$ degassing measurements, which are indicative of the physical conditions beneath the observation point. Thus, P4 on the northward inclined slope is the most suitable profile for comparing the TMF anomaly with these observations. In this case, topography does not show any sharp changes in the lateral (E-W) direction (Fig. 6c).

Figure 8a shows TMF and SP anomalies along profile $\mathrm{P} 4$. The topographic effect on SP values is already removed using the coefficient $-1.2 \mathrm{mV} / \mathrm{m}$, as given in Fig. 6c. A positive zone exists in both TMF and SP, and this coincides with the geothermal area generated by the 1992-1994 active fissures. The magnetic anomaly is most probably caused by high temperatures at shallow depth due to hydrothermal circulation. A similar feature is found along the eastern shoreline of MCL, i.e., profile P8 (Fig. 6d). However, the steep cliff of MC wall is close to the shore, which should affect TMF values along P8. As the MCL bathymetry is not known precisely, the effect of 3-D structure on TMF could not be examined.

Figure $8 \mathrm{~b}$ shows the horizontal distribution of TMF values over the Daang Kastila geothermal area, which includes the positive GT, SP, and $\mathrm{CO}_{2}$ anomalies measured along traverses P4 and P8 (Fig. 6c,d). Irregular variations of

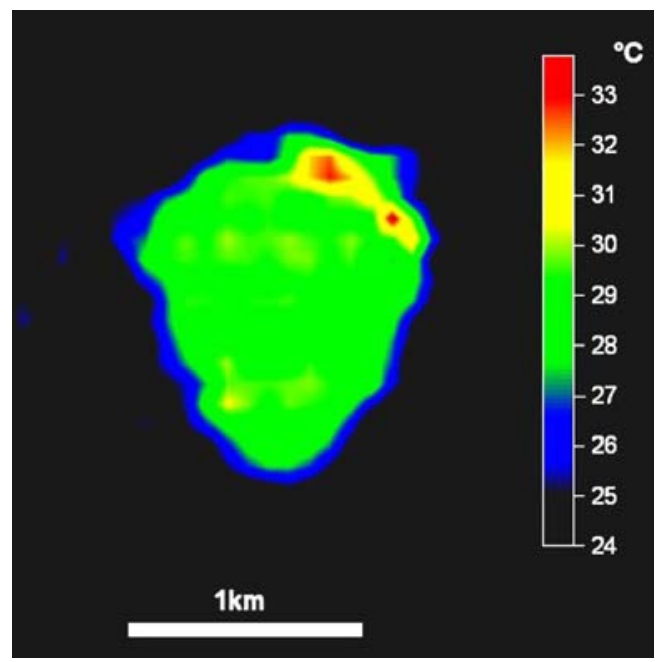

Fig. 7 ASTER thermal image recorded during the night of January 24, 2003 (at 14:16 UTC). The TIR data (band 13 and 14) were processed with a new split-window algorithm (Bernard 2008). A thermal anomaly is clearly visible in the Northern part of the lake close to the shoreline where fumarolic degassing and hot springs are located. Maximum temperatures of the two red color hot spots are, respectively, 35.7 and $34.2^{\circ} \mathrm{C}$
GT, $\mathrm{CO}_{2}$, and SP could be due to the existence of a number of fissures. Therefore, a positive TMF anomaly can be considered as a good indicator of the global heating process in rocks at shallow depth.

\section{Discussion}

The current surface activity on Taal is restricted to two well-identified areas. The main surface activity takes place on the northern part of MCL and in the inner northern part of MC with gas bubbling, solfatara, fumaroles, hot springs, and steaming grounds. The second large geothermal area is currently located on the northern MC flank near E-W fissures that were active up to 1992-1994.

Ground temperature anomalies The highest temperatures (up to $100^{\circ} \mathrm{C}$ ) are measured along the northern MCL shore line and the northernmost active 1992-1994 fissures. The largest anomalies almost follow the same curvature as the $\mathrm{MC}$ rim. Lower GTs are measured between these areas. Thermal convection prevails along these high-temperature lineaments associated with geological interfaces (MC rim, 1992-1994 fissures). Apart from these areas, conduction takes place at very shallow depth, with GT decreasing with distance to the main heat inputs (see Hochstein and Bromley 2005).

WT data of MCL indicate a two-spot anomaly along the northern shore line that traces a segment almost parallel to the 1992-1994 fissures and the MC rim (Fig. 7). As this thermal anomaly does not spread far away from this lineation and closely matches the GT anomalies measured in MC, this segment may track an active fissure (Figs. 6a, and 9a).

$\mathrm{CO}_{2}$ soil degassing Diffuse degassing of quiescent volcanoes is a powerful process leading to heat release. As mentioned previously, the Campi Flegrei solfatara may provide useful information on thermal transfers, as the site displays similar steaming grounds as observed on Taal. The thermal energy at Campi Flegrei is mainly (90\%) transported by $\mathrm{H}_{2} \mathrm{O}$ produced by aquifer boiling, and most of it is dissipated through steam condensation (Chiodini et al. 2005). This energy is much higher than that released by either seismic or deformation processes (Chiodini et al. 2001).

Fluid and heat transfers on Taal volcano are not isotropic but operate mainly from high-permeability areas such as faults, fractures, and structural discontinuities. $\mathrm{CO}_{2}$ and $\mathrm{GT}$ patterns in soils (Fig. 6), together with fumaroles, bubbling mud pools and thermal springs within Taal crater, suggest similar processes of fluid and heat transfer as well as steam condensation, even if degassing through TL also contributes to the global heat budget.

$\mathrm{CO}_{2}$ concentrations cover a wide range, from $0.02 \%$ to $100 \%$. Graphical analysis (cumulative frequency diagrams 
a
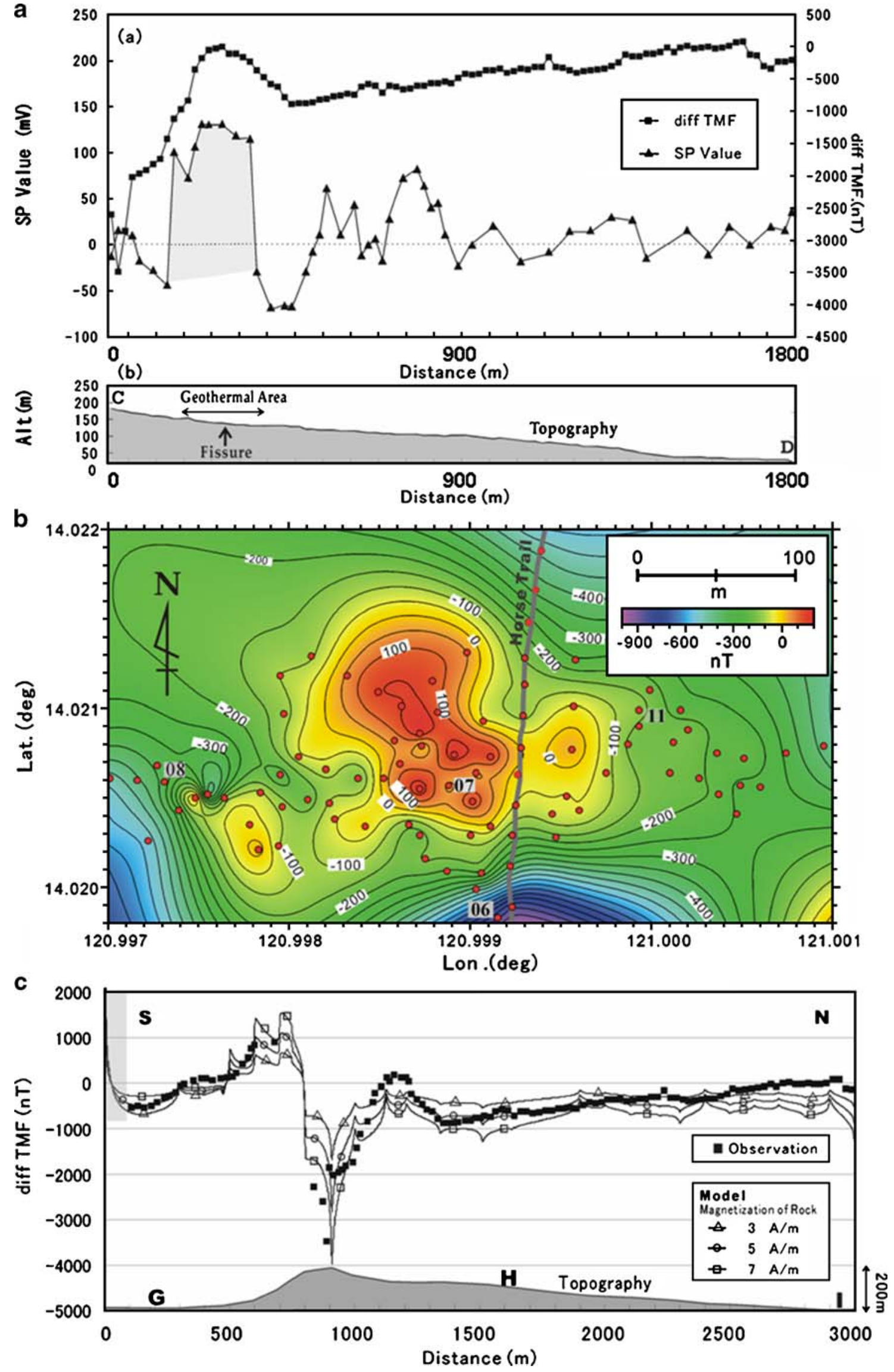
4 Fig. 8 a Top: TMF and de-trended SP anomalies from a $-1.2-\mathrm{mV} / \mathrm{m}$ topographic effect along the profile P4; a Bottom: topography along the path. b Horizontal distribution of TMF anomalies on the outer northern slope of MC (Daang Kastila). Contour interval is $50 \mathrm{nT}$. Red circles indicate the measurement spots including the repeat survey points with numerals. c Computed TMF anomalies along the profile line $G-H-I$ in Fig. 4 compared with the observations (solid squares). Solid lines with open triangles, circles, and squares indicate the computed TMF intensity, of which magnetization is assumed to be 3, 5 , and $7 \mathrm{~A} / \mathrm{m}$, respectively

which identify populations as straight lines) indicate four populations (Fig. 5): pure air, mixed air-biogenic, biogenic, and volcanic/hydrothermal gas. Concentrations higher than about $4 \% \mathrm{CO}_{2}$ are volcanic/hydrothermal gases. Such concentrations are systematically associated with visible major fractures or volcanic structures through high GT amplitude (Fig. 6a and c) and thermal anomalies in the range $75-100^{\circ} \mathrm{C}$. Concentrations below $4 \%$ are thought to be mainly characteristic of a biogenic source possibly mixed with air (Fig. 6b,c and d). Such low- $\mathrm{CO}_{2}$ anomalies are either associated with GT anomalies (Fig. 6b and d) or not (Fig. 6c). The former are likely to be the result of low hydrothermal fluid fluxes, whereas the latter are probably non-active fissures characterized by biogenic $\mathrm{CO}_{2}$ release, corresponding to superficial fissures of deep fractures being sealed by chemical and/or mechanical processes.

The $\mathrm{CO}_{2}$ map reveals the close relationship between $\mathrm{CO}_{2}$ degassing and the main structural features (Fig. 9b). A main spot of volcanic/hydrothermal gas is located within the crater on the northern shoreline of MCL, and a smaller spot is associated with the active fissures outside the crater on the northern flank, in agreement with the GT measurements. The weak $\mathrm{CO}_{2}$ anomalies, observed a few hundreds meters north of the active fissures (Fig. 6c), may characterize fissures not yet observed at the ground surface. These could be reactivated during increased activity.

SP anomalies Taal SP anomalies significantly differ from those observed in active volcanic hydrothermal systems lacking a crater lake. Sharp step-like variations of some tens of millivolts bound the anomalous areas (Figs. 6 and 9), and short-wavelength SP anomalies are correlated with GT or $\mathrm{CO}_{2}$ anomalies within geothermal areas.

Typical patterns of SP anomalies on the edge of geothermal areas can be used to infer concealed major structures. Firstly, on the northern flank of the geothermal area, a clear $-1.2 \mathrm{mV} / \mathrm{m}$ topographic effect is intersected at the break of slope by two offsets of several tens of millivolts extending up to TL (Fig. 6c). The main SP offsets correspond to the northern boundary of the geothermal area and the termination of weak $\mathrm{CO}_{2}$ anomalies (Fig. 6c). Secondly, in the northeastern part of $\mathrm{MC}$, a $100 \mathrm{mV}$ negative anomaly bounds the geothermal area to the south, and could be related to the negative anomaly west of MC northern rim (Figs. 6a and 9). This could pick out a NW-SE tectonic fault extending outside the volcano through $\mathrm{MC}$ and $\mathrm{TL}$, in accord with the location of hypocenters for previous seismic crises and the alignment of eruptive centers (Alcazar 1996; Bartel et al. 2003; PHIVOLCS internal 2005 report). In this case, this fault could represent a main groundwater channel way between MCL and TL.

The large amount of SP data leads to reliable SP mapping in the central part of the volcano (Fig. 9c and d). Two geothermal areas are well defined. The first area is mostly confined to the inner northern border of $\mathrm{MC}$, running from East to North. A second area, located on the northern flank, is expressed by a curved anomaly associated with the main active fissures outlined by $\mathrm{CO}_{2}$ and GT measurements (Figs. 1b, 6c, and d).

Cross-correlating the different observations suggests the occurrence of three elongated geothermal lineaments: (1) on the northern slope of MC, (2) between MCL shoreline and MC rim, and (3) inside MCL close to the shore. SP, TMF, $\mathrm{CO}_{2}$ degassing and GT are well correlated, and each parameter provides supplementary information. To the North, TMF data identifies a source of thermal demagnetization of rocks in the first hundreds of meters depth. SP anomalies closely follow the outline of the geothermal area and the bordering tectonic discontinuities. Local GT anomalies pick out the most active fissures associated with hydrothermal and degassing transfer, while $\mathrm{CO}_{2}$ data reveal the fissures in which degassing is taking place.

We can observe several features from Figs. 6, 7, 8b, and 9:

(1) The hydrothermal activity is emphasized along curved segments, most of them being active fissures.

(2) The source of the hydrothermal activity is located at a depth of some hundreds of meters.

(3) The presence of superficial magma can explain the observed surface activity.

(4) E-W and NW-SE trending discontinuities are located to the North and the South of these geothermal areas.

Ground deformation and seismicity also occur in these same geothermal areas. In particular, the inflation center and the hypocenters of most seismic crises are located along the northern MC rim, at a depth of a few kilometers (Bartel et al. 2003).

These observations suppose a connection between the geothermal areas located in the main crater and along the active fissures to the north (Figs. 9 and 10). At a few kilometers depth, the magma supply releases magmatic gases that generate faults. During their ascent, these gases interact with the groundwaters. Taking into account the curvature of the 1992-1994 fissures and the TMF, SP, $\mathrm{CO}_{2}$, GT, and WT anomalies, the geothermal source should be located below MC. Therefore, the E-W northern fissures of 1992-1994, which are several hundreds meters long, may 
a

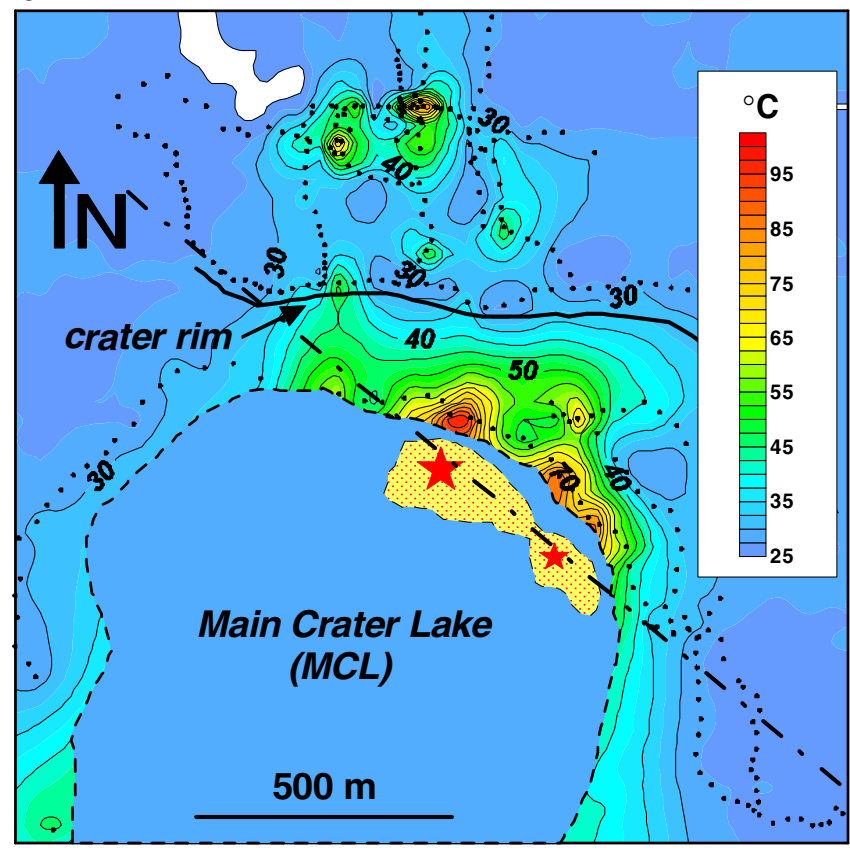

C

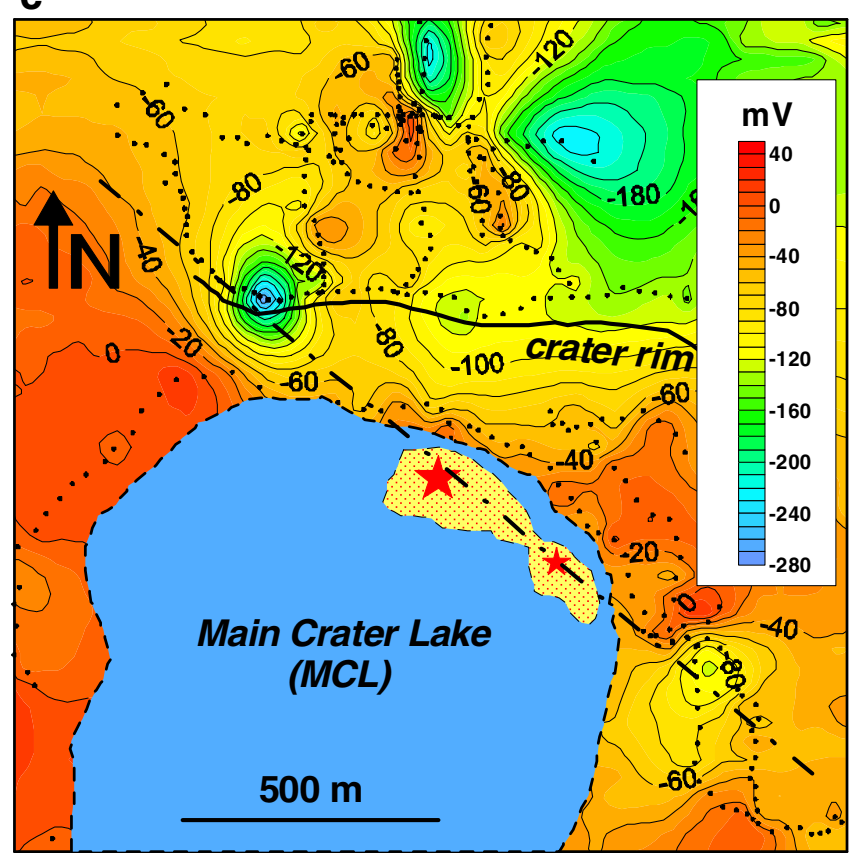

b

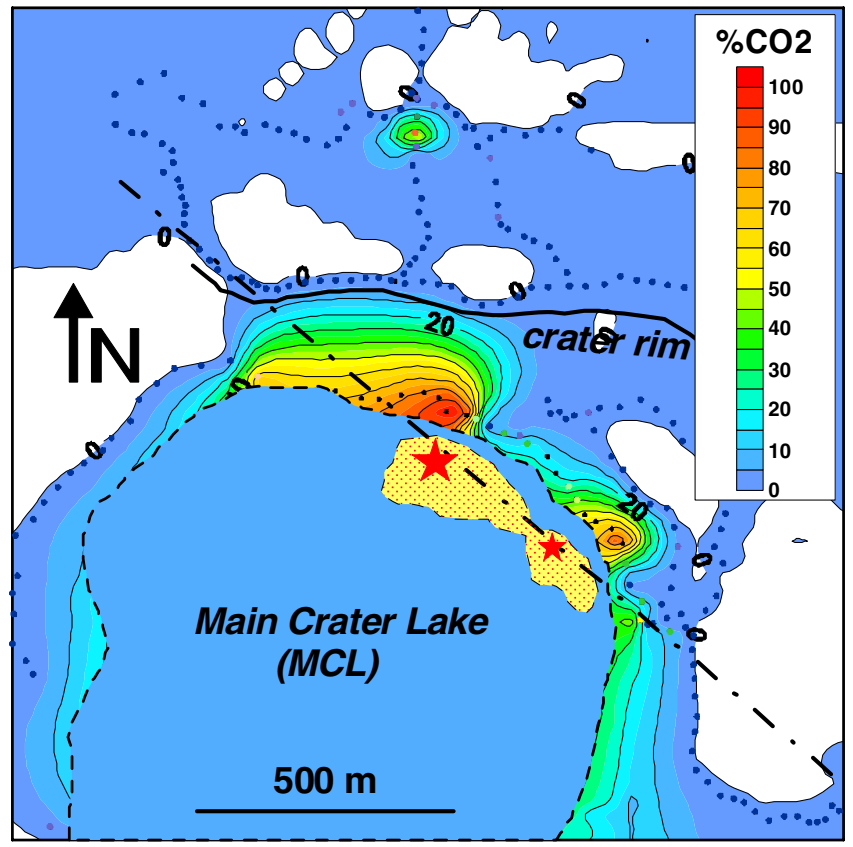

d

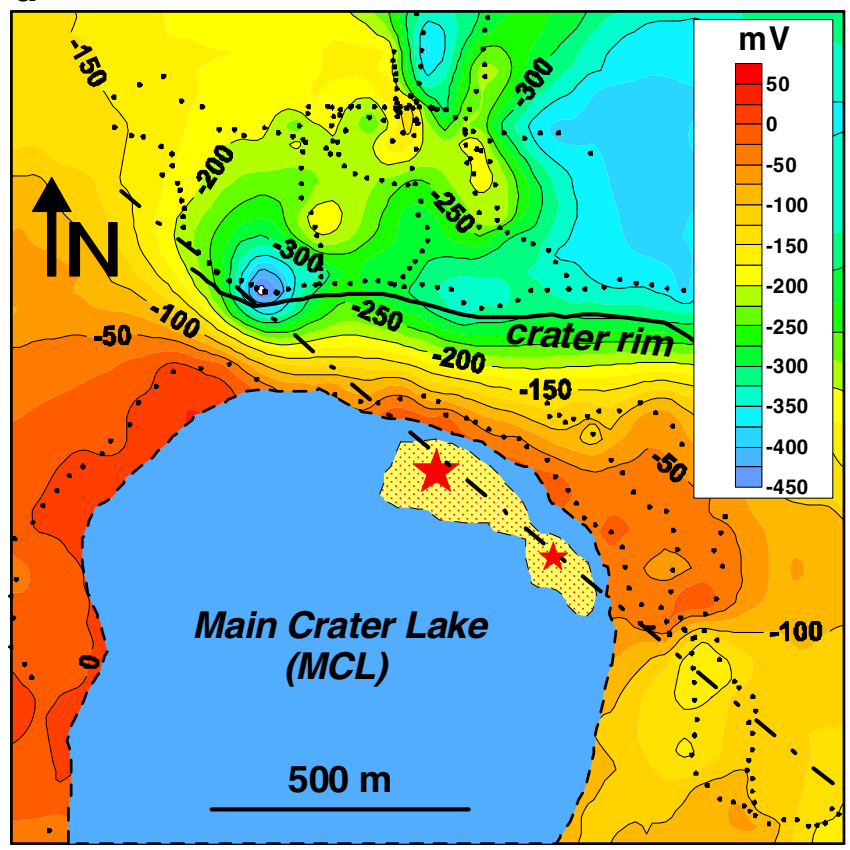

Fig. 9 Interpolated maps. a Ground temperature. $\mathbf{b} \mathrm{CO}_{2}$ soil degassing. $\mathbf{c}$ SP data. d SP data on which a mean topographic effect has been removed $(-1.2 \mathrm{mV} / \mathrm{m})$

form 'décollement fissures' that are reactivated during seismic events (see next paragraph). These fissures may potentially create instability of the northern part of the volcano, which could lead to its collapse.

Magnetic anomalies As shown in Fig. 8a,b, and c, the positive TMF anomaly could be influenced by the topogra- phy. This is because the anomaly emerges on a relatively flat portion of the northern slope with a steeper ridge (i.e., crater wall) on its southern side. At such low latitude, a higher ridge produces a positive TMF anomaly on its northern side. This possibility was examined by 2-D modeling. Figure 4 shows the profile line $G-H-I$, which runs across the peak value of positive anomalies indicated on Fig. 8a. The 


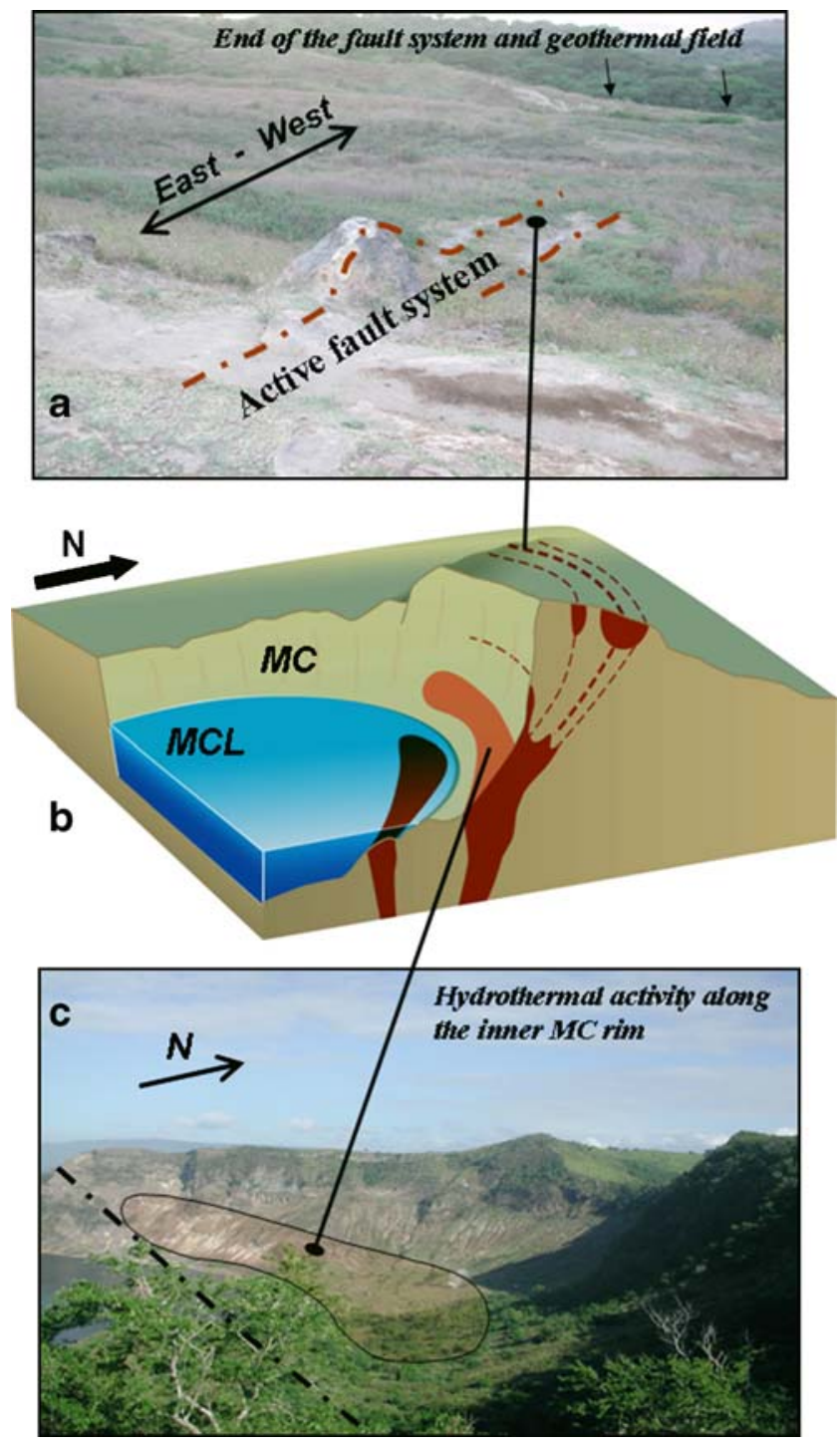

Fig. 10 a Active faults located on the northern flank. b Schematic interpretation of fluid and gas transfers in the northern part of the volcanic edifice. Red areas are the geothermal areas evidenced by the surveys. Dashed lines indicate the possible connections between the northern fissures and the geothermal area located in the main crater. c Geothermal area in the northern part of the main crater. Dashed lines indicate the trace of the NW-SE fault

volcano is assumed to be uniformly magnetized to a depth of $250 \mathrm{~m}$ below the TL surface level. We applied the 2-D modeling algorithm of Talwani and Heitzler (1964). Figure $8 \mathrm{c}$ shows the comparison of the observed and computed TMF anomalies along the line $G-H-I$. We assume magnetizations of 3,5 , and $7 \mathrm{~A} / \mathrm{m}$, but find $5 \mathrm{~A} / \mathrm{m}$ to be the most appropriate value for the overall goodness of fit. Although the computed TMF is fairly similar to the observed anomaly pattern, it cannot fully reproduce the positive anomaly in Fig. 8a. Further investigation is necessary using a 3-D modeling technique and additional measurements to assess the effect of topography on TMF anomalies.
From our modeling study, we conclude that:

(1) The positive TMF anomalies in Fig. 8a and b are mainly produced by the weakened magnetization of rocks due to the high ground temperature at shallow depth, although the effect of 3D surface topography must also be taken into account,

(2) The average magnetization of Taal volcano is $5 \mathrm{~A} / \mathrm{m}$, which will be used for further modeling studies.

\section{Temporal variation of SP and GT with volcanic activity}

SP and GT changes associated with 2005 activity On 29 October 2004, PHIVOLCS raised an alert of 1 on a fivelevel scale, after recording new volcanic earthquakes below the volcano. The seismicity decreased at the end of the year. A new seismic swarm started again on 9 January 2005 at 7:45 P.M. Several earthquakes of intensity III were felt by the islanders, who partly evacuated the volcano for a few days. Due to the small number of seismic stations, it was only possible to locate the epicenters between 1 and $4 \mathrm{~km}$ depth below the SE volcano flank. After March 2005, the seismic activity declined, and the level of alert was reduced to 0 at the end of June. Seismicity increased again in November 2005, and the alert was raised to 1 .

The P4 profile, oriented $\mathrm{N}-\mathrm{S}$ along the outer northern slope, was chosen for the reiteration of GT and SP measurements. Measurements were performed on 9 and 14 January, 22 February, 11 and 14 November 2005, and on 20 February 2006 (Fig. 11a and b). GT and SP measurements were both performed at the same locations, and several SP values were recorded by measuring the electric potential at nearby (within $1 \mathrm{~m}$ ) closed spots. GT anomalies and SP anomalies on the first $400 \mathrm{~m}$ of the profile cross the trace of active fissures.

January 2005 measurements On the northern boundary of the geothermal area, the SP topographic effect falls from -1.2 to $-0.8 \mathrm{mV} / \mathrm{m}$ between 9 and 14 January, whereas no change is recorded inside the area. The shape of the GT anomaly within the geothermal area also remains unchanged. Because of prevailing dry and constant meteorological conditions during the measurements, the decay in the SP topographic effect may be attributed to a seismically induced increase of the SP anomaly associated with an enlargement of vapor emission outside the geothermal area. Such an SP change may be related to the reactivation of small active fissures on the northern flank which are not yet observed at the ground surface. This interpretation is strengthened by the existing low-amplitude (up to 2-3\%) $\mathrm{CO}_{2}$ anomalies (Fig. 6c). 
a

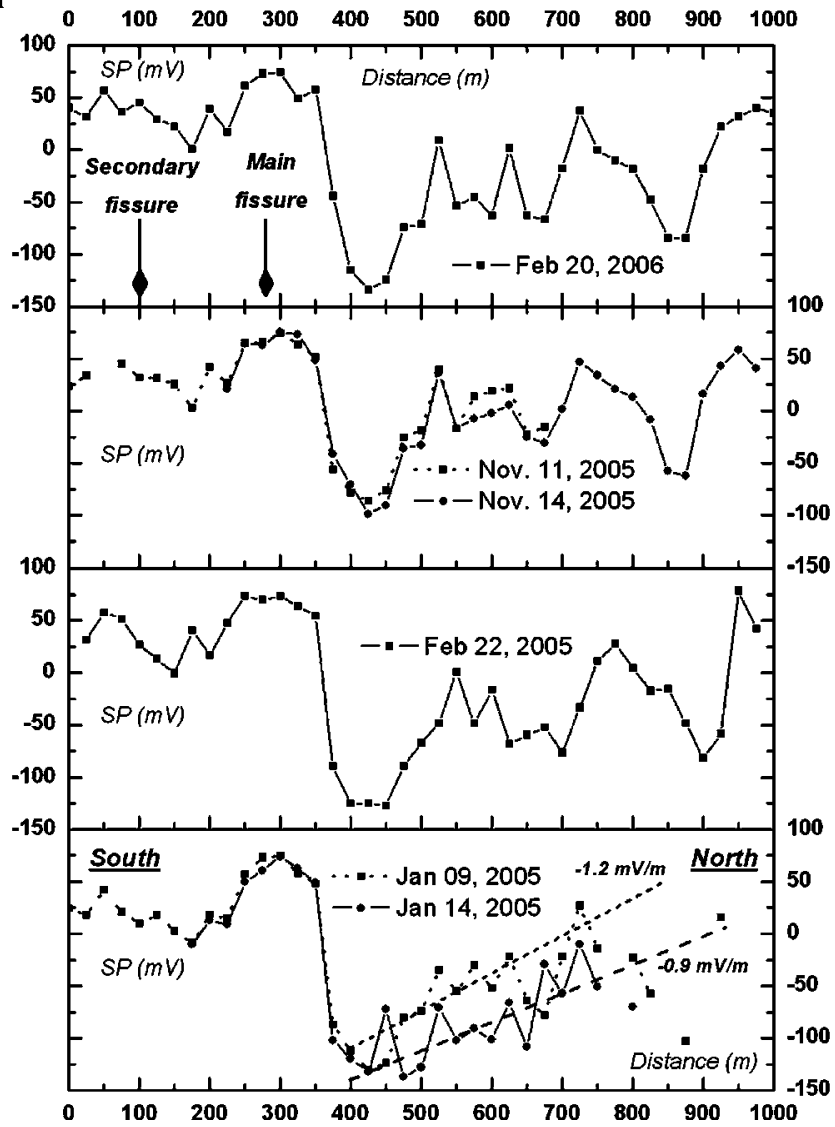

Fig. 11 Time evolution SP and GT along the P4 south-north survey crossing the northern flank fissures between November 2005 and February 2006. a SP anomalies. b ground temperature. From bottom

February 2005 measurements On 22 February 2005, the amplitude of the GT anomalies increases up to $94^{\circ} \mathrm{C}$. Higher values now extend southward from the northern fissures. Temperature increases over the anomalous zone, together with a $5-\mathrm{mV}$ increase in SP, suggesting a small rise of the global outflow. These patterns are correlated with variations of the order of $10 \mathrm{nT}$ (TMF), which correspond to a thermal demagnetization (Fig. 8c; Harada et al. 2005).

November 2005 measurements The November survey again highlights an increase in the surface activity. The SP anomalies change significantly in two sectors. Between the crater rim and the northern fissures, we record an increase of tens of millivolts, whereas the steep SP anomaly decreases from 205 to $160 \mathrm{mV}$ at the northern tip of the geothermal field. Further repeat surveys will allow us to estimate the contribution of seasonal change to this $45 \mathrm{mV}$ decay in SP. Although the general GT profile remains unchanged along P4, local variations exist: the main GT anomaly continues to increase (up to $100^{\circ} \mathrm{C}$ ), whereas the secondary GT anomaly decreases from 60 to $43^{\circ} \mathrm{C}$ above the southern secondary fissure.

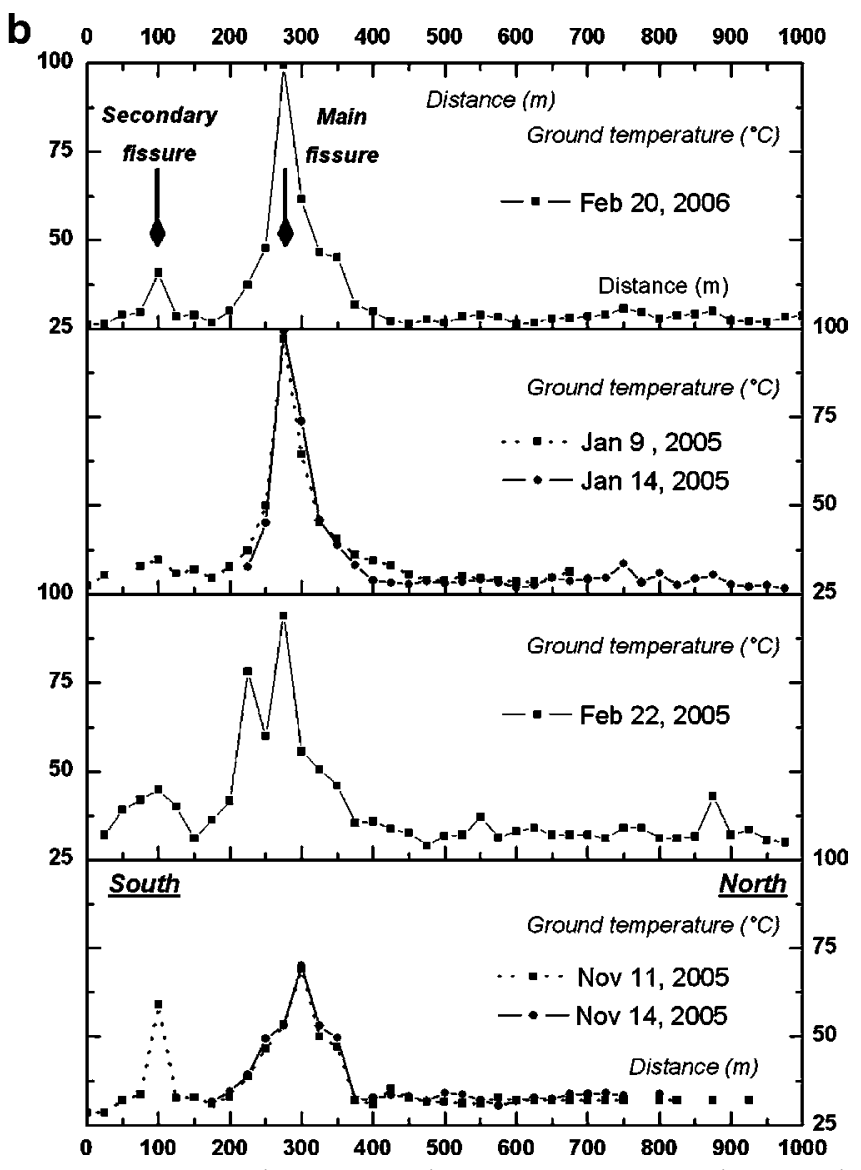

to top: January 9 and 14, 2005; February 24, 2005; November 11 and 14, 2005, and February 2006. a Ground temperature; b SP anomalies

February 2006 measurements The SP anomalies remain high from the MC rim to the tip of the geothermal area, and values seem to reach a plateau along this segment. This pattern is well-matched with the observed high-GT anomalies.

The SP and GT repeat surveys suggest that:

(1) Heat and fluid transfers increase during 2005 in correlation with seismicity.

(2) Hydrothermal activity is almost entirely controlled by two main $\mathrm{E}-\mathrm{W}$ fissures; the northernmost fissure being the major one in which $\mathrm{CO}_{2}$ soil concentrations reach $100 \%$.

(3) There is no noticeable extension of the geothermal area, although several small anomalies $\left(\mathrm{SP}, \mathrm{CO}_{2}\right)$ located north of the geothermal area could indicate non-outcropping preexisting fissures.

(4) Seismic swarms may increase the soil permeability along the main fissure, leading to increases in gas flux and ground temperature, whereas the reduced gas flux observed at the southern secondary fissure is probably the result of post-swarm mechanical and/or chemical sealing. 
The GT and SP observations made over 2005 clearly indicate that the north flank geothermal area is strongly stimulated by the seismic activity throughout the year. Heat fluxes and hydrothermal circulation are essentially located along the major fissures that currently bound the geothermal area to the north. Moreover, seismic activity could also extend the geothermal area northward.

The amplitude of the electric, temperature, and magnetic responses is notably large with respect to the weak seismicity in 2005. Therefore, the hydrothermal system could be largely disturbed by sporadic seismicity in only a few days. Releases of steam and gas, as well as eventual sudden steam explosions with high $\mathrm{CO}_{2}$ contents, may therefore occur in the event of large seismic swarm. At present, the four $1-\mathrm{Hz}$ seismic stations are insufficient to allow detailed studies linking EM signals and earthquakes mechanisms. The active geothermal area and the northernmost fissure are now monitored by a continuous GT and SP station.

Magnetic changes associated with 2005 activity At repeat survey point $P$, five readings per minute are averaged to obtain the TMF value at the observation time. Such measurements are carried out during $15 \mathrm{~min}$. The simple difference of TMF value between the survey point $P$ and the reference station $R$ is averaged over $15 \mathrm{~min}$ to give $F_{-} R(P, n)$, which is called the TMF difference at $P$ relative to $R$ at the time of $n$th survey. The difference of $\Delta F_{-} R$ between $m$ th and $n$th survey is regarded as the total intensity change during the two surveys.

Unfortunately, TMF data from Muntinlupa (MUT) were not available owing to instrumental troubles during the whole period of 8-14 January 2005, while data from BUC were not obtained for one out of three survey days between 15 and 24 February 2005 (Fig. 1b). We selected MUT as the common reference station. Here, we denote $\Delta F B$ and $F{ }_{-} M$ as the simple difference of TMF between each point and the BUC and MUT stations, respectively. In cases where MUT data are not available, we can obtain $\Delta F \_M$ as follows:

$\Delta F \_M(P, n)=\Delta F \_B(P, n)+\Delta F \_B M$

where

$\triangle F \_B M \quad$ Average of all the simple differences between BUC and MUT.

This reduction method is based on the fact that diurnal geomagnetic variations have almost the same amplitude and phase over an area of a few tens of kilometers. One of our research objectives in the future is to investigate the validity of this assumption in an equatorial region such as the Philippines, where an intense equatorial electro-jet has a prevalent effect on geomagnetic $\mathrm{Sq}$ variations.

The BUC reference station sometimes undergoes artificial disturbances owing to the movement of metallic materials (farm implements). We carefully checked the data and corrected them where possible. Moreover, at some repeat survey points, concrete benchmarks were not replaced in exactly the same position as the temporary wooden pegs, which resulted in an apparent change between the first and the second survey. Therefore, we have to discard the results of the first survey at TA15, 16, and 21 because we could not satisfactorily evaluate the reoccupation error.

Repeat survey points as shown in Fig. 4 belong to the following three areas: (A) east shore of the MCL and the southeastern slope outside MC, (B) Daang Kastila, the outer northern slope of MC, and (C) west shore of the MCL and the outer western slope of MC. Each area displays a significant geothermal activity, particularly in (A) and (B).

Field work started on 9 January 2005, when five benchmarks were established (points TA01 to TA05) on the eastern shore of MCL. As stated above, some strong earthquakes (intensity III) occurred in the evening. An increase in fumarolic activity was noticed during the survey, and hence the first five stations were reoccupied on 14 January. The total intensity relative to BUC was found to increase by $2.5 \mathrm{nT}$ at three sites (T01, T02, and T03) in area (A), which forms part of the eastern geothermal area within MC. The observed changes in the total intensity are sufficient to be significant because the spatial difference of the geomagnetic diurnal variation is negligibly small in such a local area (Buco reference station is only $8 \mathrm{~km}$ away from the centre of the MCL).

Figure 12a,b, and c show the TMF changes at repeat survey points relative to MUT during the period from January 2005 to February 2006 in areas (A), (B), and (C), respectively. In area (A), the total intensity increased by several nanoTesla and remained constant at TA02 and TA03, which are located in the geothermal area. In the southern half of the eastern MCL and the outer southeastern slope of MC, there were no noticeable changes in TMF. Figure 14 shows a view of the geothermal zone on the eastern MCL shore on (a) 8 January and (b) 25 February 2005. The vegetation was clearly withered at that time, while the fumarole later became active within 1.5 months. The increase in TMF at TA03 and TA02 is most probably associated with a rise in the shallow ground temperature.

Changes in TMF are most prominent in area (B). From January to February 2005, TMF increases by almost $10 \mathrm{nT}$, remaining high and then recovering in November. These magnetic signals are clearly correlated with the increase of GT anomaly and a decrease of the topographic effect on SP (Fig. 11a and b). However, the variation at the northernmost point TA10 is somewhat doubtful. It is located in a very local hollow, which might be affected by the inflow of mud due to heavy tropical rain. As the variation at TA09 is relatively small, the temperature rise is thought to have occurred farther south from this site as shown in Fig. 11a. Although TA17 and TA08 are located east and west of the fumarole zone, the 
a

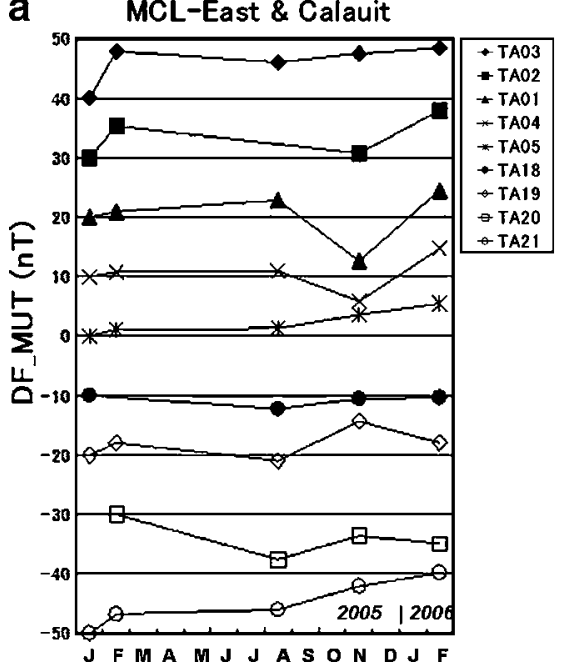

b

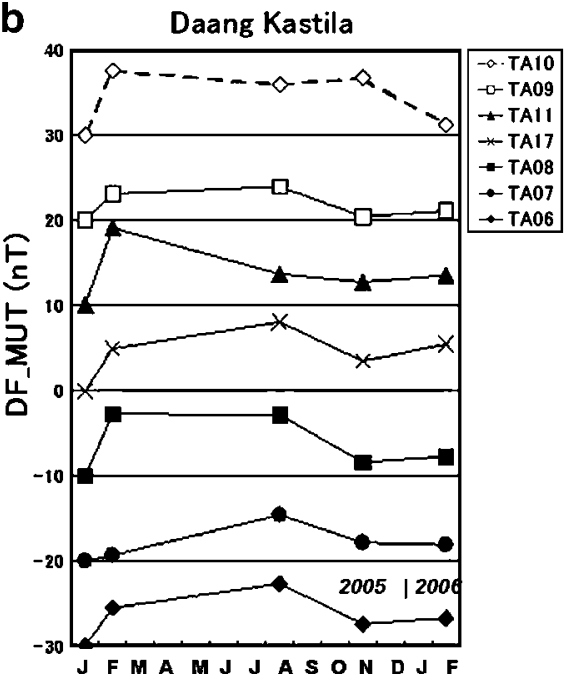

C MCL-West \& Alas-as

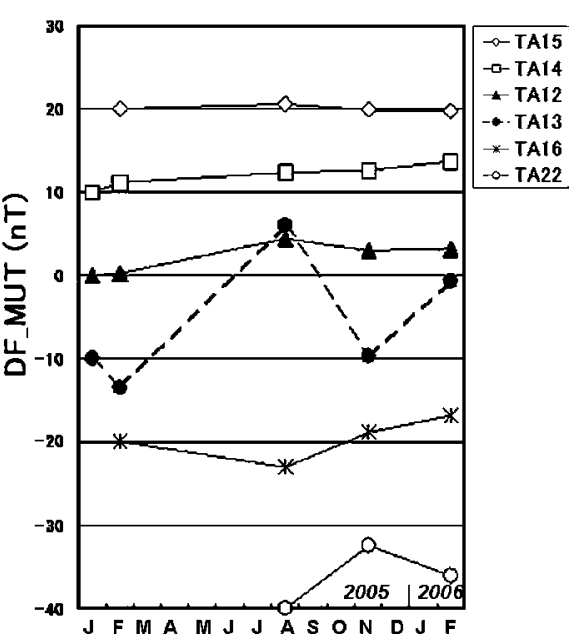

Fig. 12 a Changes in the total intensity in the area $(A)$, the eastern shore of MCL and the outer south-eastern slope of MC. b Changes in the total intensity in the area $(B)$, the outer northern slope of $\mathrm{MC}$

increase in TMF and its recovery are clearly seen. It is noteworthy that the TMF change is rather small at TA07, which occupies a central position in the fumarolic zone.

In area (C), only TA13 is located within a fumarolic zone. However, we find that the vertical gradient of TMF is abnormally high at this site: the large variation at TA13 could be due to the reoccupation error of the magnetometer sensor. From the variations at TA12, 14, and 15, we can conclude that there was no enhancement of geothermal activity on the western shore of the MCL during 2005. This strongly suggests that the source of the geothermal activity in the western MCL is isolated and independent from those of the eastern MCL and Daang Kastila.

Let us consider the cause of TMF changes. During the period from January to February 2005, GT is seen to rise in
(Daang Kastila). $\mathbf{c}$ Changes in the total intensity in the area $(C)$, the western shore of MCL and the outer western slope of MC

the geothermal area. According to GT and SP data along the profile P1 (Fig. 6a) and the temperature distribution obtained by ASTER satellite imagery (Fig. 6b), we may reasonably expect to find a high-temperature zone elongated roughly WNW-ESE on the northeastern side of the MCL. We assume that a horizontally embedded ellipsoid in this zone has lost some of its magnetization. The formula for the magnetic field produced by a uniformly magnetized triaxial ellipsoid can be derived by differentiating the gravity potential due to the same body (Kellogg 1929). The equation is equivalent to the formula given by Clark et al. (1986).

Figure 13a shows the TMF changes produced by a demagnetized ellipsoid assumed to be located just beneath the northeastern corner of the Main crater, corresponding to a very thin flat-shaped magnetic body. The model param-

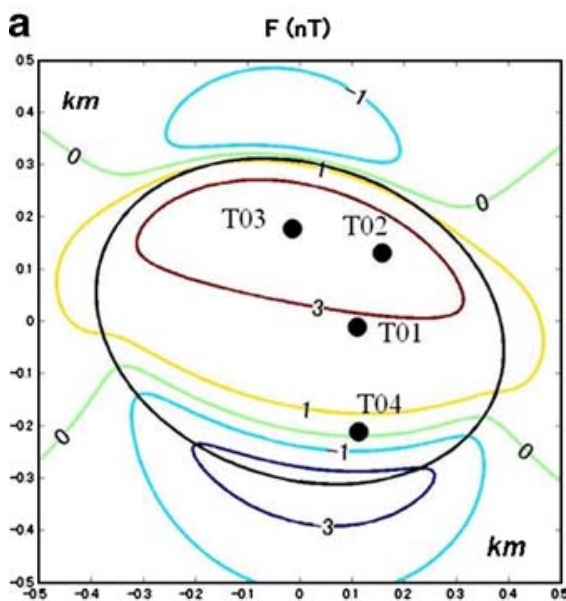

b

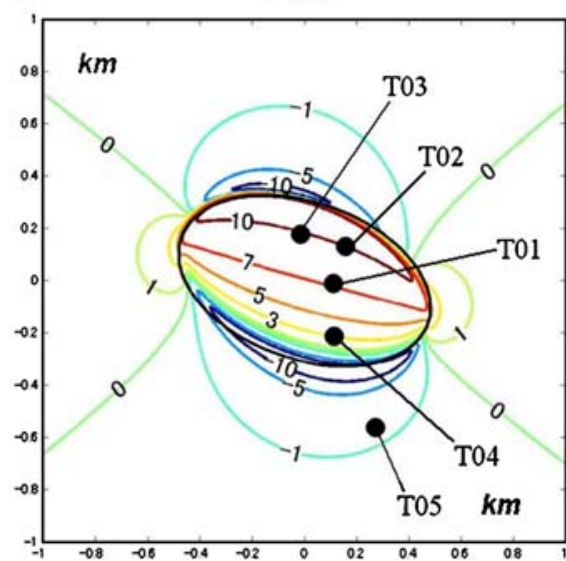

C $\quad F(n T)$

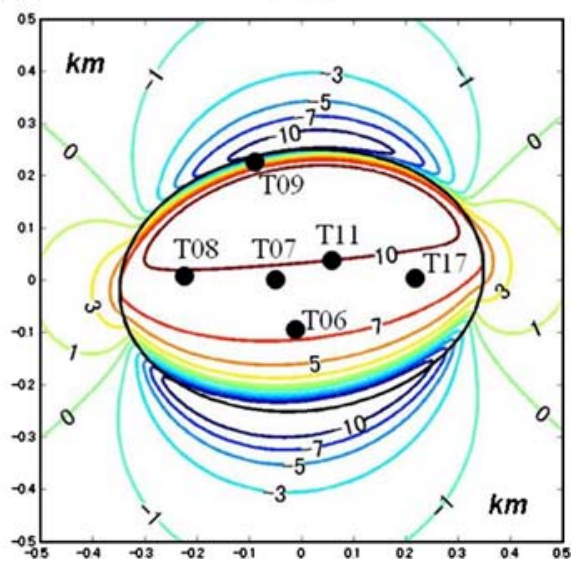

Fig. 13 a TMF changes produced by a flat triaxial ellipsoid of model (a) in Table 1. The solid line indicates the horizontal projection of the ellipsoid to the ground surface. Solid circles with the station number are repeat survey points. Unit in $\mathrm{nT}$. The horizontal distance (in $\mathrm{km}$ ) is given along the frame. $\mathbf{b}$ TMF changes produced by an ellipsoid of Model (b), which is the same one as Model (a) but lies at a depth of $10 \mathrm{~m}$ instead of $50 \mathrm{~m}$. c TMF changes produced by an ellipsoid of Model (c). Values on a northward inclined plane are plotted 
Table 1 Model parameters for uniformly demagnetized ellipsoids

\begin{tabular}{lccc}
\hline Parameters & Model (a) & Model (b) & Model (c) \\
\hline Major axis length & $400 \mathrm{~m}$ & $500 \mathrm{~m}$ & $350 \mathrm{~m}$ \\
Minor axis length & $300 \mathrm{~m}$ & $300 \mathrm{~m}$ & $250 \mathrm{~m}$ \\
Vertical thickness & $50 \mathrm{~m}$ & $50 \mathrm{~m}$ & $100 \mathrm{~m}$ \\
Depth of the top surface & $50 \mathrm{~m}$ & $10 \mathrm{~m}$ & $15 \mathrm{~m}$ \\
Orientation of major axis & $\mathrm{N} 115^{\circ} \mathrm{E}$ & $\mathrm{N} 115^{\circ} \mathrm{E}$ & $\mathrm{N} 80^{\circ} \mathrm{E}$ \\
Magnetization & $-0.5 \mathrm{~A} / \mathrm{m}$ & $-0.5 \mathrm{~A} / \mathrm{m}$ & $-0.5 \mathrm{~A} / \mathrm{m}$ \\
Geomagnetic inclination & $14^{\circ}$ & $14^{\circ}$ & $9.2^{\circ}$ \\
Geomagnetic declination & $0^{\circ}$ & $0^{\circ}$ & $0^{\circ}$ \\
\hline
\end{tabular}

eters are given in Table 1a. The total intensity values are computed at a height of $2.5 \mathrm{~m}$ above the ground surface. This model shape accounts very well for the TMF change of $+2.5 \mathrm{nT}$ observed in the eastern MCL during the period from 9 to 14 January 2005.

As shown in Fig. 14, the rise in GT led to withering of the grass near the shore, and it is reasonable to assume that the zone of high ground temperatures ascended to a shallower depth in February. Figure $13 \mathrm{~b}$ shows TMF changes in the case where the top surface of the same ellipsoid lies at a depth of $10 \mathrm{~m}$ from the ground surface. This explains the TMF changes at TA03 and TA02 between the surveys of January and February 2005. As the average magnetization of Taal volcano is estimated as $5 \mathrm{~A} / \mathrm{m}$, a demagnetization of $1 \%$ is sufficient to produce the observed TMF changes. Such a demagnetization would be attained by a temperature rise of a few or several degrees, although we require thermal-magnetic experiments on rock samples from Taal volcano. However, we do not detect the negative anomalies that would be expected outside the northern and southern edges of such an ellipsoid. In area (A), while no repeat survey points could be placed to the north because of the steep crater wall, TA04 and TA05 occupy positions that are used to identify the southern border of the source. Figure $13 \mathrm{~b}$ shows that TA04 is close to the southern boundary of the subsurface heated area. As TA05 is located at a higher elevation, the expected TMF change is much less than the value shown in Fig. 13 b.

Similarly, in area (B), the observations could be interpreted by a slightly demagnetized ellipsoid almost in the E-W orientation as shown in Fig. 13c, using the model parameters given in Table 1(c). As the survey points are located on a northward facing slope with an inclination $4.8^{\circ}$, TMF values are computed at a height of $2.5 \mathrm{~m}$ above this inclined surface. This can be performed by simply assuming the geomagnetic dip as $9.2^{\circ}$. Figure $13 \mathrm{c}$ gives a possible source for the remarkable TMF changes in Daang Kastila from January to February 2005. The source ellipsoid is bounded between TA09 and TA06 in a N-S direction, while it extends in an E-W direction outside TA08 and TA17. This suggests that the subsurface hightemperature zone expanded during the early 2005 activity. We find no negative anomaly zone on the northern and southern sides of the survey area. To the south, the steep cliff of MC prevents the installation of a survey point. More points will later be established farther north. Most probably, the thermal demagnetization would have taken place nonuniformly rather than in such a simple-shaped body as an ellipsoid. However, we should stress that a temperature rise of only a few degrees Celsius at a depth of $15 \mathrm{~m}$ below the ground surface can explain the general trend of TMF changes in this area. This does not conflict with the fact that we observed no noticeable withering of vegetation during the activity of January to March 2005.

\section{Concluding remarks}

Since almost a decade, Taal volcano has shown signs of a forthcoming eruption. During the 1992-1994 seismic crises, fissures opened on the northern flank of the volcano. Recurrent seismic swarms are regularly recorded associated with ground deformation. Since 1994, weak vapor emission has occurred in the area, and the geothermal field has
Fig. 14 a Northeastern part of main crater on January, 8, 2005. b Northeastern part of main crater on February, 22, 2005. Note withered vegetation in February 2005
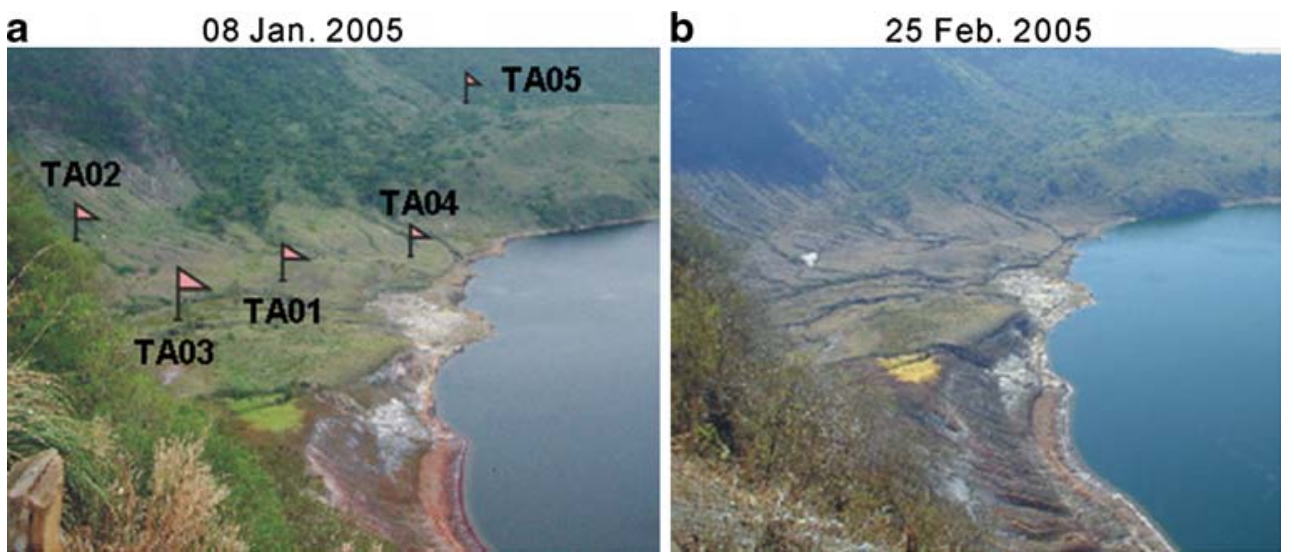
expanded. Integrated studies started on the volcano in early 2005. Combined electromagnetic, geochemical, and thermal imaging surveys were performed to improve our understanding of the extent, evolution, and reactivity of the hydrothermal system, as well as assess the thermal state of the volcano. These parameters appear to have controlled the strength of most of the Taal eruptions.

Combined SP, GT, WT, $\mathrm{CO}_{2}$, and TMF surveys indicate that the northern part of the volcano is undergoing strong thermal transfers and degassing. The activity takes place along $\mathrm{E}-\mathrm{W}$ fissures that could be linked to the root of the northern border of $\mathrm{MC}$ at a depth of some hundreds of meters and also connected to a thermal source near the MCL shore line. This thermal source location could be the initial spot of the next eruptive activity. In such a case, strong activity could induce a collapse of a part of the northern MC rim into the MCL, due to mechanical weakening by the active 1992-1994 fissures. To the south, this system appears to be bounded by a NW-SE fault suspected from the NW-SE alignment of negative SP and WT anomalies in the MC. Seismic activity and dike injection may be taking place along this alignment. Changes in SP, TMF, and GT are measured by means of repeat profiles, suggesting that potentially hazardous phreatic and gas eruptions may be associated with future seismic unrest in these geothermal areas.

Acknowledgements This work was primarily supported by ElectroMagnetic studies of Earthquakes and Volcanoes Inter-association working group (EMSEV) with the financial support of the International Union of Geophysics and Geodesy (IUGG) and its associations (IAGA-IASPEI-IAVCEI). We greatly thank Dr Renato Solidium Jr., Director of the Philippine Institute of Volcanology and Seismology (PHIVOLCS), and Prof. Seiya Uyeda, Chair of EMSEV, for the setting up of a long-term cooperation agreement in Electromagnetic research. We are also greatly indebted to Dr. Bartolome Bautista and the EM PHIVOLCS team, P.D. Reniva, C.S. Saquilon, Paul K.B. Alanis, Melchor P. Lasala, I.C. Narag, and R.P.R. Maximo as well as the seismologic group for their very efficient help in the field organization and during the campaign. Research on Taal, considered as a high-risk volcano, is supported by the Demeter 2006 program, run by CNES, (National French Spatial Agency) and the Ministry of Foreign Affairs (French Embassy, Manila). We are very grateful to Pr Delmelle for his useful comments. Prof R.B. Trombley of the International Volcano Research Centre (INTLVRC, http://www. intlvrc.org/) helped us in the editorial work.

\section{References}

Alcazar A (1996) Surveillance of Taal volcano. Philipp Geol 20:1-13 Allard P, Carbonnelle J, Dajlevic D, Le Bronec J, Morel P, Robe MC, Maurenas J, Faivre-Pierret MR, Martin D, Sabroux JC, Zettwoog $\mathrm{P}$ (1991) Eruptive and diffuse emissions of $\mathrm{CO}_{2}$ from Mount Etna. Nature 351:387-391

Aubert M, Baubron JC (1998) Identification of a hidden thermal fissure in a volcanic terrain using a combination of hydrothermal convection indicators and soil-atmosphere analysis. J Volcanol Geotherm Res 35:217-225

Ballestracci R, Nishida Y (1987) Fracturing associated with 1977-1978 eruption of Usu volcano, North Japan, as revealed by geophysical measurements. J Volcanol Geotherm Res 34:107-121

Bartel BA (2002) Magma dynamics at Taal volcano, Philippines from continuous GPS measurements. MS thesis, University of Indiana, Bloomington

Bartel BA, Hamburger MW, Meertens CM, Lowry AR, Corpuz E (2003) Dynamics of magmatic and hydrothermal systems at Taal volcano, Philippines, from continuous GPS measurements. J Geophys Res 108:2475 DOI 10.1029/2002JB002194

Baubron JC, Allard P, Toutain JP (1990) Diffuse volcanic emissions of carbon dioxide from Vulcano island, Italy. Nature 344: $51-53$

Baubron JC, Allard P, Sabroux JC, Tedesco D, Toutain JP (1991) Soil gas emanations as precursory indicators of volcanic eruptions. J Geol Soc London 148:571-576

Bernard A (2008) A split window algorithm for measuring the temperature of volcanic lakes with ASTER satellite. J Volcanol Geotherm Res (in press)

Byrdina S, Friedel S, Wassermann J, Zlotnicki J (2003) Self-potential variations associated with ultra-long-period volcanic earthquakes at Merapi volcano. Geophys Res Lett 30:2156 DOI 10.1029/ 2003GL018272

Camarda M, De Gregorio R, Favara G, Gurrieri S (2007) Evaluation of carbon isotope fractionation of soil $\mathrm{CO}_{2}$ under an advectivediffusive regime: a tool for computing the isotopic composition of unfractionated deep source. Geochim Cosmochim Acta 71:3016-3027 DOI 10.1016/j.gca.2007.04.002

Cardellini C, Chiodini G, Frondini F (2003) Application of stochastic simulation to $\mathrm{CO}_{2}$ flux from soil: mapping and quantification of gas release. J Geophys Res 108:2425 DOI 10.1029/2002JB002165

Chiodini G, Frondini F, Cardellini C, Granieri D, Marini L, Ventura G (2001) $\mathrm{CO}_{2}$ degassing and energy release at Solfatara volcano, Campi Flegrei, Italy. J Geophys Res 106:16213 DOI 10.1029/ 2001JB000246

Chiodini G, Todesco M, Caliro S, Del Gaudio C, Macedonio G, Russo M (2003) Magma degassing as a trigger of bradyseismic events: the case of Phlegrean Fields (Italy). Geophys Res Lett 30:1434 DOI 10.1029/2002GL016790

Chiodini G, Granieri D, Avino L, Caliro S, Costa A (2005) Carbon dioxide diffuse degassing and estimation of heat release from volcanic and hydrothermal systems. J Geophys Res 110:B08204 DOI 10.1029/2004JB003542

Clark DA, Saul SJ, Emerson DW (1986) Magnetic and gravity anomalies of a triaxial ellipsoid. Explor Geophys 17:189-200

Corwin RF, Hoover DB (1979) The self-potential method in geothermal exploration. Geophysics 44:226-245

Delmelle P, Kusakabe M, Bernard A, Fischer T, De Brouwer S, Del Mundo E (1998) Geochemical and isotopic evidence for seawater contamination of the hydrothermal system of Taal volcano, Luzon, the Philippines. Bull Volcanol 59:562-576

Di Maio R, Di Sevo V, Giammetti S, Patella D, Piscitelli S, Siniscalchi A (1996) Self potential anomalies in some Italian volcanic areas. Ann Geofis 39:179-188

Di Vito MA, Isaia R, Orsi G, Southon J, De Vita S, Di Antonio M, Pappalardo L, Piochi M (1999) Volcanism and deformation since 12,000 years at the Campi Flegrei caldera (Italy). J Volcanol Geotherm Res 91:221-246

Farrar CD, Sorrey ML, Evans WC, Howles JF, Kerr BD, Kennedy BM, King CY, Southon JR (1995) Forest-killing diffuse $\mathrm{CO}_{2}$ emission at Mammoth Mountain as a sign of magmatic unrest. Nature 376:675-678

Finizola A, Lénat JF, Macedo O, Ramos D, Thouret JC, Sortino F (2004) Fluid circulation and structural discontinuities inside Misti 
volcano (Peru) inferred from self-potential measurements. J Volcanol Geotherm Res 135:343-360

Friedel S, Byrdina S, Jacobsa F, Zimmer M (2004) Self-potential and ground temperature at Merapi volcano prior to its crisis in the rainy season of 2000-2001. J Volcanol Geotherm Res 134:149-168

Gabinette E (1999) Interpretation of the 1992 and 1994 ground deformation data at Taal volcano, Batangas, Phillip Inst Volcanol Seismol in-house workshop, Quezon City

Gaeta FS, De Natale G, Peluso F, Mastrolorenzo G, Castagnolo D, Troise C, Pingue F, Mita DG, Rossano S (1998) Genesis and evolution of unrest episodes at Campi Flegrei caldera: the role of thermal fluid-dynamical processes in the geothermal system. J Geophys Res 103:20921 -20933 DOI 10.1029/97JB03294

Harada M, Sabit J, Sasai Y, Alanis PKB, Cordon JM Jr, Corpuz EG, Zlotnicki J, Nagao T, Punongbayan JT (2005) Magnetic and electric field monitoring at Taal volcano, Part I: Magnetic measurements. Proc Japan Acad 81(B):261-266

Hashimoto T, Tanaka Y (1995) A large self-potential anomaly on Unzen volcano, Shimabara peninsula, Kyushu Island, Japan. Geophys Res Lett 22:191-194

Hernandez PA, Notsu K, Salazar JM, Mori T, Natale G, Okada H, Virgili G, Shimoike Y, Sato M, Perez NM (2001) Carbon dioxide degassing by advective flow from Usu volcano, Japan. Science 292:83-86

Hochstein MP, Bromley CJ (2005) Measurement of heat flux from steaming ground. Geothermics 34:133-160

Hurst AW, Rickerby PC, Scott BJ, Hashimoto T (2004) Magnetic field changes on White Island, New Zealand, and the value of magnetic changes for eruption forecasting. J Volcanol Geotherm Res 136:53-70

Ishido T, Mizutani H (1981) Experimental and theoretical basis of electrokinetic phenomena in rock-water systems and its applications to geophysics. J Geophys Res 86:1763-1775

Kellogg OD (1929) Foundation of potential theory. Springer-Verlag, Berlin

Klusman RW (1993) Soil gas and related methods for natural resource exploration. John Wiley \& Sons Ltd, Chichester

Johnston MJS, Stacey FD (1969) Volcano-magnetic effect observed on Mt Ruhapehu, New Zealand. J Geophys Res 74:6541-6544

Johnston MJS, Byerlee JD, Lockner D (2001) Rapid fluid disruption: a source for self-potential anomalies on volcanoes. J Geophys Res 106:4327-4336

Lewicki JL, Connor C, St-Amand K, Stix J, Spinner W (2003a) Selfpotential, soil $\mathrm{CO}_{2}$ flux, and temperature on Masaya volcano, Nicaragua. Geophys Res Lett 30:1817 DOI 10.1029/2003GL017731

Lewicki JL, Evans WC, Hilley GE, Sorey ML, Rogie JD, Brantley SL (2003b) Shallow soil $\mathrm{CO}_{2}$ flow along the San Andreas and Calaveras faults, California. J Geophys Res 108:2187 DOI 10.1029/2002JB002141

Massenet F, Pham VN (1985) Mapping and surveillance of active fissures zones on a volcano by self-potential method, Etna, Sicily. J Volcanol Geotherm Res 24:315-338

McGee KA, Gerlach TM, Kessler K, Doukas MP (2000) Geochemical evidence for a magmatic $\mathrm{CO}_{2}$ degassing event at Mammoth Mountain, California, September-December 1997. J Geophys Res 105:8447 -8456 DOI 10.129/2001JB000407

Michel S, Zlotnicki J (1998) Self-potential and magnetic surveying of La Fournaise volcano (Réunion Island): correlations with faulting, fluid circulation and eruption. J Geophys Res 103:17845 -17857 DOI 10.1029/98JB00607

Nourbehecht B (1963) Irreversible thermodynamic effects in inhomogeneous media and their application in certain geoelectric problems. PhD thesis, MIT, Cambridge

Overbeek JT (1952) Irreversible systems. Colloid science, vol. 1. Elsevier, New York

Perrier FD, Petiau G, Clerc G, Bogorodsky V, Erkul E, Jouniaux L, Lesmes D, Macnae J, Meunier JM, Morgan D, Nascimento D, Oettinger G, Schwarz G, Toh H, Valiant MJ, Vozoff K, YaziciCakin O (1997) A one-year systematic study of electrodes for long period measurements of the electric field in geophysical environments. J Geomag Geoelectr 49:1677-1696

Petiau G (2000) Second generation of lead-lead chloride electrodes for geophysical applications. Pageoph 157:357-382

Poussielgue N (1998) Signal acoustique et activité thermique dans les lacs de cratère de volcans actifs. Réalisation d'une station de mesure hydroacoustique au Taal (Philippines). PhD thesis, Université de Savoie, Chambery

Ramos EG (1986) Lakeshore landslides: unrecognized hazards around Taal volcano. Phil J Volcanol 3:28-53

Ramos EG (2001) Geomorphic features of Taal volcano. J Geol Soc Phil 56(3-4):105-124

Sasai Y, Shimomura T, Hamano Y, Utada H, Yoshino T, Koyama S, Ishikawa I, Nakagawa I, Yokoyama Y, Ohno M, Watanabe H, Yukutake T, Tanaka U, Yamamoto T, Nakaya K, Tsunomura S, Muromatsu F, Murakami R (1990) Volcanomagnetic effect observed during the 1986 eruption of Isu-Oshima volcano. J Geomag Geoelect 43:291-317

Sasai Y, Zlotnicki J, Nishida Y, Yvetot P, Morat P, Murakami H, Tanaka Y, Ishikawa Y, Koyama S, Sekiguchi W (1997) Electromagnetic monitoring of Miyake-jima volcano, Izu Bonin arc, Japan: a preliminary report. J Geomag Geoelectr 49:1293-1316

Sasai Y, Uyeshima M, Zlotnicki J, Utada H, Kagiyama T, Hashimoto T, Takahashi Y (2002) Magnetic and electric field observations during the 2000 activity of Miyake-jima volcano, Central Japan. Earth Planet Sci Lett 203:769-777

Sato M, Mooney HM (1960) The electrochemical mechanism of sulfide self-potentials. Geophysics 25:226-249

Talwani M, Heitzler JR (1964) Computation of magnetic anomalies caused by two-dimensional structures of arbitrary shape. In: Parks GA (ed) Computers in the mineral industries. Stanford University Press, Leland, California, pp 464-480

Tanaka Y (1993) Eruption mechanism as inferred from geomagnetic changes with special attention to the 1989-1990 activity of Aso Volcano. J Volcanol Geotherm Res 56:319-338

Todesco M, Chiodini G, Macedonio G (2003) Monitoring and modelling hydrothermal fluid emission at la Solfatara (Phlegrean Fields, Italy). An interdisciplinary approach to the study of diffuse degassing. J Volcanol Geotherm Res 125:57-79

Toutain JP, Baubron JC, Francois L (2002) Runoff control of soil degassing at an active volcano. The case of Piton de la Fournaise, Reunion Island. Earth Planet Sci Lett 197:83-94

Yukutake T, Yoshino T, Utada $\mathrm{H}$, Watanabe $\mathrm{H}$, Hamano $\mathrm{Y}$, Shimomura T (1990) Changes in the electrical resistivity of the central cone, Mihara-yama, of Oshima volcano observed by a direct current method. J Geomag Geoelectr 42:151-168

Zlotnicki J, Le Mouël JL (1988) Volcanomagnetic effects on Piton de la Fournaise Volcano (Réunion Island). J Geophys Res 93:91579171

Zlotnicki J, Nishida Y (2003) Morphological insights of self-potential anomalies on volcanoes. Surv Geophys 24:291 DOI 10.1023/B: GEOP.0000004188.67923.ac

Zlotnicki J, Boudon G, Le Mouël JL (1992) The volcanic activity of la Soufrière of Guadeloupe (Lesser Antilles): structural and tectonic implications. J Volcanol Geotherm Res 49:91-104

Zlotnicki J, Boudon G, Voidé JP, Delarue JF, Mille A, Bruère F (1998) Hydrothermal circulation beneath Mount Pelée inferred by selfpotential surveying: structural and tectonic implications. J Volcanol Geotherm Res 84:73-91

Zlotnicki J, Sasai Y, Yvetot P, Nishida Y, Uyeshima M, Fauquet F, Utada H, Takahashi Y, Donnadieu G (2003) Resistivity and self-potential changes associated with volcanic activity: The July 8, 2000 Miyakejima eruption (Japan). Earth Planet Sci Lett 205(3-4):139-154

Zohdy AA, Anderson RLA, Muffler LJP (1973) Resistivity, selfpotential and induced polarization surveys of a vapor-dominated geothermal system. Geophysics 38:1130-1144 